\title{
Pre-Bout Neural Activity Changes in Premotor Nucleus HVC Correlate with Successful Initiation of Learned Song Sequence
}

\author{
- Raghav Rajan \\ Division of Biology, Indian Institute of Science Education and Research Pune, Pashan, Pune, Maharashtra, 411008 India
}

Preparatory activity, characterized by gradual, longer timescale changes in neural activity, is present in a number of different brain areas before the onset of simple movements and is believed to be important for movement initiation. However, relatively little is known about such activity before initiation of naturally learned movement sequences. The song of an adult male zebra finch is a well studied example of a naturally learned movement sequence and previous studies have shown robust premotor activity immediately before song. Here, I characterize longer timescale changes in neural activity in adult male zebra finch premotor nucleus HVC before onset of song bouts. I show that interneurons and a subset of basal-ganglia-projecting neurons change their activity several hundred milliseconds before song bout onset. Interneurons increased their activity, whereas basal-ganglia-projecting neurons either increased or decreased their activity. Such changes in neural activity were larger, started earlier, and were more common specifically before song bouts that began with the short, repetitive, introductory notes (INs) characteristic of zebra finch song bouts. Further, stronger and earlier changes were also correlated with successful song sequence initiation. Finally, a small fraction of basal-ganglia-projecting neurons that increased their activity before song bout onset did not have song or IN-related activity, suggesting a specialized preparatory role for such neurons. Overall, these data suggest that pre-bout activity in HVC represents preparatory activity important for initiation of a naturally learned movement sequence.

Key words: bird song; learned movement sequences; premotor; preparatory activity; zebra finch

Significance Statement

Changes in neuronal activity well before the onset of simple movements are thought to be important for movement initiation. However, a number of animal movements consist of sequences of simple movements and relatively little is known about neuronal activity before such movement sequences. Using adult zebra finch song, a well studied example of a movement sequence, I show here that neurons in premotor nucleus HVC change their activity hundreds of milliseconds before song bout onset. In most neurons, the presence of such changes correlated with successful song sequence initiation. My results show the presence of preparatory neural activity in HVC and suggest a role for $\mathrm{HVC}$ in sequence initiation in addition to its established role in song sequence timing.

\section{Introduction}

In 1965, Kornhuber and Deecke observed increased activity in the human brain hundreds of milliseconds before the onset of a simple self-timed finger-tapping movement and termed this ac-

\footnotetext{
Received 0ct. 19, 2017; revised May 11, 2018; accepted May 15, 2018.

This work was supported by the Human Frontier Science Program (Long-Term Fellowship LT00759/2007-L to R.R.), the Department of Biotechnology, Govt. of India (Ramalingaswami Fellowship BT/HRD/35/02/2006 to R.R.), the Science and Engineering Research Board, Department of Science and Technology, Govt. of India (Grant EMR/ 2015/000829 to R.R.), and the National Institutes of Health (Grant R01 MH55987 to Allison Doupe). I thank Allison Doupe and Michael Brainard (at University of California-San Francisco) for support and guidance; Adria Arteseros for help with histology; Divya Rao and Harini Suri for providing songs from two birds for analysis; Upinder Bhalla, Nixon Abraham, and Michael Long for helpful discussions; and Mimi Kao, Hamish Mehaffey, Anand Krishnan, Deepa Subramanyam, Prathima Rajan, Divya Rao, Harini Suri, and Shikha Kalra for comments on the manuscript.

The author declares no competing financial interests.
}

tivity as "Bereitschaftpotential" or "readiness potential." In subsequent decades, much work has demonstrated similar "preparatory" activity before movement initiation in many different brain areas in many different animal model systems (Romo and Schultz, 1987; Schultz and Romo, 1992; Lee and Assad, 2003; Churchland et al., 2006, 2010; Maimon and Assad, 2006; Jin and Costa, 2010, 2015; Shenoy et al., 2013; Li et al., 2015, 2016; Chen et al., 2017). Manipulating preparatory activity in these circuits

Correspondence should be addressed to Raghav Rajan, Division of Biology, Indian Institute of Science Education and Research Pune (IISER Pune), Dr. Homi Bhabha Road, Pashan, Pune, Maharashtra, 411008 India. E-mail: raghav@iiserpune.ac.in.

DOI:10.1523/JNEUROSCI.3003-17.2018

Copyright $\odot 2018$ the authors $\quad 0270-6474 / 18 / 385925-14 \$ 15.00 / 0$ 
can activate, suppress, or delay movement initiation, suggesting its importance for movement initiation (Day et al., 1989; Churchland and Shenoy, 2007; Kravitz et al., 2010; Guo et al., 2014; Li et al., 2015, 2016). Much of this work has been done in animals trained to perform a simple cue-triggered reaching movement. However, a number of movements that we perform involve self-initiated, learned movement sequences, such as a tennis player's serve, and preparatory activity preceding such self-initiated, learned movement sequences remains poorly understood.

One such well studied example of a learned movement sequence is the song of an adult male zebra finch, a songbird (Fee and Scharff, 2010). The song motif is a stereotyped sequence of sounds interleaved with silent periods and is learned by young birds in a manner similar to human speech learning (Doupe and Kuhl, 1999; Bolhuis et al., 2010). Song motifs are organized into larger units called song bouts that typically begin with a variable number of short sounds called introductory notes (INs) before production of mutiple song motifs (Price, 1979; Sossinka and Böhner, 1980; Rajan and Doupe, 2013). Song bouts are part of a courtship ritual triggered by presence of a female, but male zebra finches also sing when they are alone (undirected song; Sossinka and Böhner, 1980), providing an excellent model system with which to study neural activity before self-initiated, learned movement sequences.

Song is controlled by two discrete pathways in the zebra finch brain: (1) a motor pathway (see Fig. 1A, black) consisting of two cortex-like nuclei, HVC and RA, that connect to syringeal and respiratory motor neurons and (2) an anterior forebrain pathway (AFP, Fig. 1A, gray), which is homologous to mammalian cortical basal ganglia circuits, involving an indirect connection from HVC to RA (Fee and Scharff, 2010). Neurons in all of these areas are active immediately before ( $\sim 50 \mathrm{~ms})$ and during song motif syllables and INs (McCasland, 1987; Yu and Margoliash, 1996; Hessler and Doupe, 1999; Hahnloser et al., 2002; Williams and Vicario, 1993; Leonardo and Fee, 2005; Kao et al., 2008; Goldberg and Fee, 2012; Rajan and Doupe, 2013; Vyssotski et al., 2016). However, this activity occurs immediately before vocalization, unlike preparatory activity, which typically shows gradual, longer timescale changes before movement onset (Kornhuber and Deecke, 1965; Shenoy et al., 2011). Such longer timescale preparatory activity has been shown to occur in the input and output nuclei of the AFP (Hessler and Doupe, 1999; Kao et al., 2008; Woolley et al., 2014), but the origin of this activity and its role in song initiation is unclear.

Here, I test the idea that preparatory neural activity before song bout onset is present in HVC, a major input to the AFP (Fortune and Margoliash, 1995), by analyzing activity of HVC neurons in singing birds. I found that both interneurons and Area $\mathrm{X}$-projecting neurons in $\mathrm{HVC}$ changed their activity hundreds of milliseconds before song bout onset. These changes were specific to song bouts that began with INs. Further, a small fraction of Area X-projecting neurons that increased their activity well before song bout onset did not fire during INs or song, suggesting a preparation-specific role for these neurons. Finally, stronger and earlier changes were correlated with successful song sequence initiation, suggesting the importance of these changes for song bout initiation.

\section{Materials and Methods}

Experiments and animals. Experiments were performed at the University of California-San Francisco (UCSF) and at the Indian Institute of Science Education and Research (IISER) Pune. All procedures were ap- proved by the UCSF Institutional Animal Care and Use Committee and were performed in accordance with National Institutes of Health guidelines. Experiments performed at IISER Pune were approved by the Institute Animal Ethical Committee in accordance with the guidelines of the Committee for the Purpose of Control and Supervision of Experiments on Animals (New Delhi, India). Adult male zebra finches $(n=8$ for electrophysiological recordings and $n=9$ for song recordings, $>90 \mathrm{~d}$ posthatch) were either purchased from outside sources or bred at UCSF or IISER Pune. Birds were housed individually in acoustically isolated enclosures (Acoustic Systems/Newtech Engineering Systems) for the period of the experiment with a $14 \mathrm{~h}$ (light): $10 \mathrm{~h}$ (dark) cycle.

Details of overlap with previous studies. In this study, I report on the activity of $56 \mathrm{HVC}$ neurons and six putative outside-HVC neurons. Motif-related activity of $27 \mathrm{HVC}_{\mathrm{X}}$ (12 antidromically identified and 15 putative) neurons (Woolley et al., 2014) and IN-related activity of 46 $\mathrm{HVC}$ neurons (12 antidromically identified $\mathrm{HVC}_{\mathrm{X}}$ neurons, 18 putative $\mathrm{HVC}_{\mathrm{X}}$ neurons and 16 putative interneurons; Rajan and Doupe, 2013) have been described in earlier studies. In this study, I have added data from seven additional HVC neurons (one antidromically activated $\mathrm{HVC}_{\mathrm{X}}$ neuron, five putative $\mathrm{HVC}_{\mathrm{X}}$ neurons, and one putative interneuron). One putative $\mathrm{HVC}_{\mathrm{X}}$ neuron from an earlier study (Woolley et al., 2014) was not included in this study because it was not recorded during undirected song.

Surgery and electrode implantation. Details of surgical procedures are described in prior studies (Rajan and Doupe, 2013; Woolley et al., 2014). Briefly, each bird was deeply anesthetized with equithesin, fixed in a custom stereotaxic apparatus, and implanted with a custom-made microdrive containing 3-4 tungsten micro-electrodes (FHC; impedance 5-10 M $\Omega$ ) targeting right HVC. An uninsulated ground electrode was placed in the contralateral hemisphere. The microdrive was cemented to the skull using dental cement (A-M Systems). Birds were given an oral analgesic (meloxicam) 30 min before surgery and were also monitored on a regular basis for signs of pain or discomfort after surgery. After surgery, analgesics were given if the bird showed signs of discomfort. In three of the birds, two stainless steel electrodes (A-M Systems) were implanted $500 \mu \mathrm{m}$ apart in Area X for antidromic verification of $\mathrm{HVC}_{\mathrm{X}^{-}}$ projecting neurons. However, I was able to obtain successful evoked spikes and collision only in two of the birds. Two of the microdrives also had a screw for adjusting the lateral position of the electrodes. Each time the electrodes had been moved through HVC, they were retracted out of $\mathrm{HVC}$ and the electrodes were moved laterally to enable a new penetration through HVC.

Song and neural recordings. Details of song and neural recordings are described in prior studies (Rajan and Doupe, 2013; Woolley et al., 2014). Briefly, 1 week after surgery, birds were connected up to a custom-made unity gain preamplifier circuit that was attached to a commutator (Dragonfly). Birds were attached to the preamplifier throughout for a period of $2-3$ weeks with regular monitoring to ensure that the birds did not get tangled up. Signals from the preamplifier were further amplified using a Neuralynx Lynx-8 amplifier and recorded on the computer using custom-written software controlling a data acquisition card (National Instruments, NI 6052E). Neural signals were recorded at $32 \mathrm{kHz}$ and song was simultaneously recorded at the same rate using a microphone (B3 omnidirectional lavalier microphone; Countryman Associates) placed above the cage. For 38 HVC neurons, song and neural activity were recorded on a triggered basis every time the signal from the microphone crossed a preset threshold. Three to $6 \mathrm{~s}$ of data immediately before trigger crossing and 3-6 s of data immediately after trigger crossing were recorded, along with data during the trigger crossing period. For 35 neurons, I also recorded short duration files (10-60 s) with no singing for estimation of spontaneous activity. In addition, for a small number of units $(n=18)$, both song and neural data were recorded continuously (median duration of continuous recording $=17.15 \mathrm{~min}$; range $=1.6-$ $133.1 \mathrm{~min})$.

All of the songs were recorded in the undirected condition when the bird's cage was placed alone inside an acoustically isolated enclosure. For one of the birds, the door of the sound box was kept open to allow the bird to hear other birds or colony sounds were occasionally played back through a speaker to encourage the bird to sing. The speaker was turned 
off as soon as the bird began to sing and, typically, the bird continued to sing a few bouts even though the speaker was off.

For the birds recorded for analysis of solitary IN bouts, signals from the microphone were recorded continuously using custom-written software for periods ranging from $4-14 \mathrm{~h}$ at $32 \mathrm{kHz}(n=5)$ or at $44.1 \mathrm{kHz}(n=6)$.

Data analysis. All data analysis was done using custom-written scripts in MATLAB (RRID:SCR_001622).

Spike sorting. Spikes were sorted as described previously (Rajan and Doupe, 2013; Woolley et al., 2014). Briefly, spikes were detected by crossing of a preset threshold (a refractory period of $0.5 \mathrm{~ms}$ prevented repeated detection of the same spike) and various different features (peak, valley, and the first three principal components) were calculated for each of the detected spikes. These features were used to automatically classify all spikes into different clusters using KlustaKwik (K.D. Harris: https:// sourceforge.net/projects/klustakwik/). The resulting clusters were then curated manually by merging clusters with similar waveforms. In all but one of the sites, sorting yielded only one unit that was used for further analysis (the exception being one site where two separate clusters were used: one putative interneuron and one putative $\mathrm{HVC}_{\mathrm{X}}$ neuron). Spike times were extracted and stored for further analysis. For $80 \%$ of the units, $\leq 0.2 \%$ of interspike intervals (ISIs) were $<1 \mathrm{~ms}$ (median fraction of ISIs $<1 \mathrm{~ms}$ across all neurons $=0.05 \%$; range $=0-0.56 \%$ ).

The signal-to-noise ratio (SNR) for each unit was calculated as described previously (Bankman et al., 1993). Briefly, all waveforms for a given unit were upsampled fourfold, aligned on the peak, and an average waveform was calculated. SNR of the unit was calculated as the ratio of the root mean square of the average waveform to the SD of the entire data. Median SNR for HVC interneurons was 3.37 (range $=1.97-5.38$ ); median SNR for $\mathrm{HVC}_{\mathrm{X}}$ neurons was 4.39 (range $=2.31-9.49$ ); median SNR for outside-HVC neurons was 7.27 (range $=2.62-10.36$ ). SNR for neurons shown in Figures $1 D$ and $2 D=6.2$; for those shown in Figures $1 E$ and $2 C=2.8$; for those shown in Figure $2 B=5.97$; and for those shown in $5 A=2.62$.

Classification of neurons. Similar to previous studies (Swadlow, 1998; Hahnloser et al., 2002; Kozhevnikov and Fee, 2007; Long et al., 2010; Rajan and Doupe, 2013; Woolley et al., 2014; Kosche et al., 2015), 13 of the single units were classfied as $\mathrm{HVC}_{\mathrm{X}}$-projecting neurons based on the presence of a reliable antidromic spike with low latency variability (median latency variability: $0.065 \mathrm{~ms}$; range: $0.027-0.42 \mathrm{~ms}$ ) after stimulation in Area X. Latency variability was calculated as the SD of the times of the antidromically evoked spike. Collision was verified in all 13 cases.

The rest of the units were classified using spontaneous firing rate (calculated from -2000 to $-1500 \mathrm{~ms}$ before bout onset), average motifrelated firing rate, and motif-related firing sparseness. Only units that were recorded for $\geq 3$ motifs were considered. Figure $1 B$ shows motifrelated firing sparseness index, a measure of whether the neuron fires uniformly throughout the motif $(0)$ or fires only at specific discrete times within the motif ( 1 if it fires only once during the motif). Spike trains were first aligned to the motif with median length using time-warping methods described previously (Hahnloser et al., 2002; Leonardo and Fee, 2005; Kozhevnikov and Fee, 2007; Kao et al., 2008; Long et al., 2010; Woolley et al., 2014). Warped spikes from each motif rendition were binned at 3 ms resolution, averaged across all motif renditions, and convolved with a Gaussian kernel $(\sigma=5 \mathrm{~ms}$, length $=3 \sigma)$. Bins with zero firing rate were converted to a very small nonzero number $(0.000000001)$ and the entire histogram was normalized such that the sum equaled 1. Motif sparseness index was then calculated similar to previous studies (Lehky et al., 2005; Ölveczky et al., 2011) as follows:

$$
\text { Motif sparseness index }=1+\sum_{\mathrm{i}=1: \mathrm{n}}\left(\mathrm{p}_{\mathrm{i}}^{\star} \log \left(\mathrm{p}_{\mathrm{i}}\right)\right) / \log (\mathrm{n})
$$

where $p_{\mathrm{i}}$ refers to each bin of the convolved, normalized peristimulus time histogram (PSTH), and $n$ refers to the total number of bins. As described previously (Hahnloser et al., 2002; Kozhevnikov and Fee, 2007; Long et al., 2010), units recorded in this study could also be divided into two clusters based on these two attributes. Putative $\mathrm{HVC}_{\mathrm{X}}$ neurons had lower motif-related firing rates and higher motif sparseness when compared with putative interneurons (Fig. $1 B$; motif-related firing rates: me- dian $=120.9 \mathrm{~Hz}$ and range $=37.7-205.6 \mathrm{~Hz}$ for putative interneurons vs median $=8.4 \mathrm{~Hz}$ and range $=0-21.7 \mathrm{~Hz}$ for putative and antidromically identified $\mathrm{HVC}_{\mathrm{X}}$ neurons; motif-firing sparseness: median $=0.07$ and range $=0.03-0.18$ for putative interneurons vs median $=0.57$ and range $=0.42-0.73$ for putative and antidromically identified $\mathrm{HVC}_{\mathrm{X}}$ neurons). All putative $\mathrm{HVC}_{\mathrm{X}}$ neurons $(n=26)$ had nonzero spontaneous activity (median $=2.95 \mathrm{~Hz}$ and range $=0.25-8.14 \mathrm{~Hz}$ ) and had similar motif-related firing rates and sparseness as antidromically identified HVC $_{\mathrm{X}}$ neurons $(n=13$; Fig. $1 \mathrm{~B}, C)$. I also recorded two other units with no spontaneous activity and one stereotyped burst each during the song motif. These were classified as putative $\mathrm{HVC}_{\mathrm{RA}}$-projecting neurons based on previous descriptions of such neurons (Hahnloser et al., 2002; Kozhevnikov and Fee, 2007; Long et al., 2010). These were not considered further and are not included in any part of this study.

In addition to these neurons, I also recorded from a small sample of neurons $(n=6)$ that were classified as "outside" HVC neurons for the following reasons. These neurons were encountered after sequentially recording many sites with singing-related activity characteristic of HVC. These neurons did not have singing-related activity (see Fig. 5A,B) and multiunit activity at these sites did not have singing-related activity either. Moving further down did not yield new sites with singing-related activity, suggesting that these sites were ventral to HVC, possibly in $\mathrm{HVC}_{\text {shelf }}$. Some of these sites responded to sounds, but this was not rigorously quantified.

Song bout identification, labeling, and classification. Vocalizations were segmented into syllables based on crossings of an amplitude threshold. Syllables with gaps $<5 \mathrm{~ms}$ between them were merged and syllables $<10$ $\mathrm{ms}$ in duration were discarded. Syllables were then given labels based on their spectral properties. This was done in a semiautomatic procedure in which syllables were first classified using template-matching procedures or clustered using KlustaKwik based on syllable features calculated using MATLAB code for SoundAnalysisPro (http://soundanalysispro.com/ matlab-library). Syllable labeling was verified manually using visual inspection of spectrograms for all files.

Groups of labeled syllables were segmented into bouts based on the presence of $>2 \mathrm{~s}$ of silence before and after the syllable group. The repetitive motif (stereotyped sequence of syllables interleaved by gaps that is characteristic for each bird) was identified and bouts were further categorized into four types (see Fig. 2A) as follows: (1) IN song bouts were bouts that started with an IN and contained at least one motif syllable; typically, these bouts had only introductory notes before the start of the first motif syllable and included one or more full motifs; (2) call-IN song bouts were bouts that started with a call and contained at least one motif syllable (typically included INs and one or more full motifs); (3) call bouts were bouts that started with a call and did not include any motif syllables; typically, these bouts contained isolated calls or multiple calls produced with gaps $<2$ s between them; and (4) solitary IN bouts were bouts that started with an IN and did not contain any motif syllables; typically, these bouts contained single INs, a small number of INs, or an IN and a few calls.

Characterization of pre-bout activity. Pre-bout activity was characterized by comparing activity in a $500 \mathrm{~ms}$ pre-bout activity window $(-600$ to $-100 \mathrm{~ms}$ before bout onset) with activity in another $500 \mathrm{~ms}$ spontaneous activity window ( -2000 to $-1500 \mathrm{~ms}$ before bout onset) using Wilcoxon sign-rank test (MATLAB function signrank). The last $100 \mathrm{~ms}$ before bout onset was not considered because this window represents premotor activity related to the upcoming syllable (McCasland, 1987; Yu and Margoliash, 1996; Hahnloser et al., 2002; Schmidt, 2003; Kozhevnikov and Fee, 2007) and the aim of this study was to examine longer-term changes that precede bout onset. A neuron was considered for a given bout type only if it had been recorded for $\geq 3$ bouts of that type.

Previous studies have also used nonvocalization periods that are separated from vocalizations by $>3 \mathrm{~s}$ as a measure of spontaneous activity (Hessler and Doupe, 1999; Kao et al., 2008). I did not have such data for all neurons and so did not use this measure. However, for the subset of neurons with such data, I estimated spontaneous activity from $500 \mathrm{~ms}$ bins during such periods ( $n=37$ neurons with $\geq 15$ such periods; median number of such baseline periods $=178$; range $=16-7212)$. This 
A

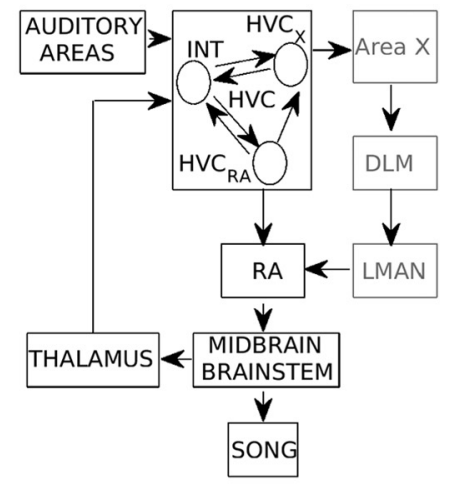

B

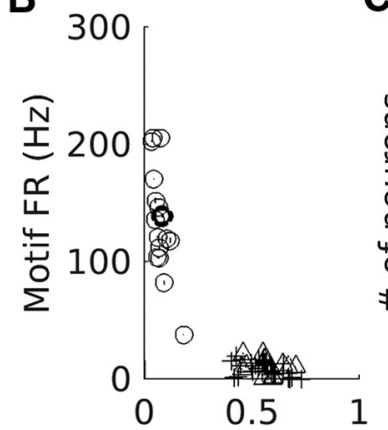

C

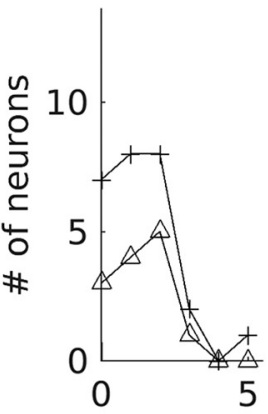

Sparseness Index \# of bursts during the motif

D

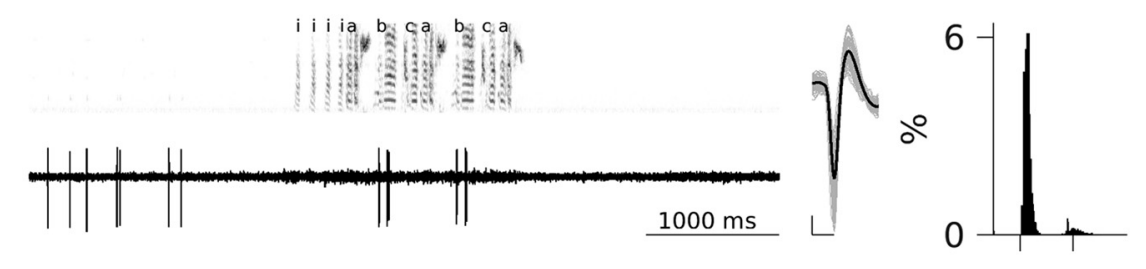

E
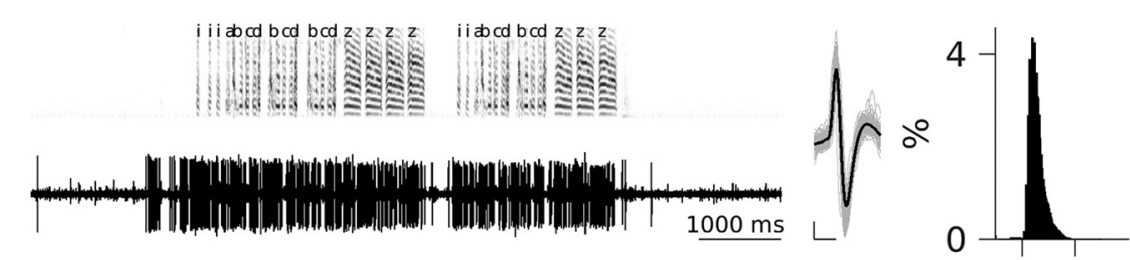

1100

$\mathbf{F}$
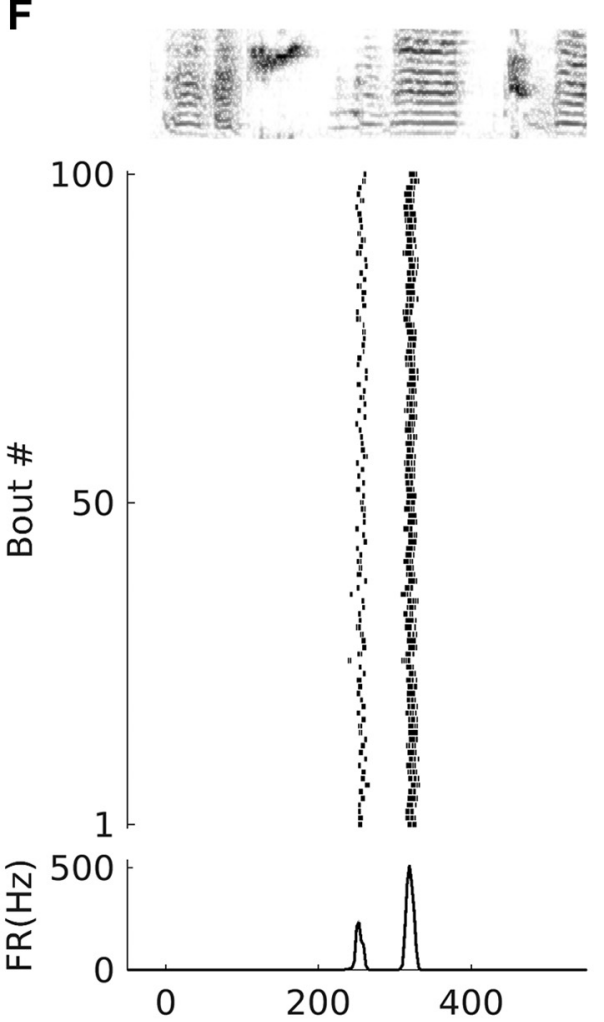

G ISI (ms)

Time relative to bout onset (msec) Time relative to bout onset (msec)

Figure 1. Classification of recorded neurons and motif-related firing of one putative $H V C_{x}$ unit and a putative interneuron. $A$, Song control pathways in the zebra finch brain are depicted. The vocal motor pathway, shown in black, consists of two nuclei, HVC and RA, which control song production through their connections to brainstem and midbrain nuclei. Shown in gray is the anterior forebrain pathway, the songbird equivalent of a mammalian cortex basal ganglia thalamocortical circuit. This pathway originates in premotor nucleus HVC and ends in motor nucleus (Figure legend continues.) 
was then compared with pre-bout activity before IN song bouts using a Kruskal-Wallis test. $79.2 \%$ of the neurons $(n=19 / 24)$ continued to show significant differences in pre-bout activity in the same direction, validating the use of the spontaneous activity window $(-2000$ to -1500 ms) before bout onset.

To verify that window location and duration did not affect the results, the same analysis was also repeated with pre-bout activity window ranging in duration from 900 to $100 \mathrm{~ms}$. In all cases, spontaneous activity window began at $-2000 \mathrm{~ms}$ before bout onset and ended at $-1500 \mathrm{~ms}$ before bout onset. Pre-bout activity window always ended at $-100 \mathrm{~ms}$ before bout onset. $92.3 \%$ of interneurons (12/13) and $73.3 \%(11 / 15)$ of $\mathrm{HVC}_{\mathrm{X}}$ neurons showed significant changes in all of the windows considered. These results showed that pre-bout activity changes were robust and occurred hundreds of milliseconds before bout onset.

Estimation of latency of neural activity changes. The time when neural activity changed was estimated at the level of individual neurons as follows. Spike trains before bout onset for each bout were binned with $1 \mathrm{~ms}$ resolution and then convolved with a Gaussian kernel $(\sigma=20 \mathrm{~ms}$, length $=3 \sigma)$. The $95 \%$ confidence intervals of spontaneous activity for each millisecond bin were obtained by resampling 10,000 times from the spontaneous activity window (MATLAB function bootstrp). The maximum and minimum of these were taken as upper and lower confidence intervals for spontaneous activity for each neuron. The time at which the average firing rate went outside these confidence intervals and stayed outside up to bout onset was considered as the time of change. There was no estimate for neurons in which the firing rate remained within the confidence intervals. SE estimates for the latency were calculated as previously described (Maimon and Assad, 2006). Briefly, data from all of the relevant bouts were resampled with replacement to generate an artificial dataset with same number of bouts as the original dataset. The latency when neural activity changed was estimated for the artificial dataset as outlined above and this was repeated for 100 such resampled datasets. The SD of latency estimates from this resampling procedure was considered as the SE for the original latency measurement for each neuron (see Fig. 6B).

For $\mathrm{HVC}_{\mathrm{X}}$ neurons that decreased their firing rate, an alternative procedure was also used to estimate latency. The time at which activity changed was estimated by finding the median last spike time across all relevant bouts during a time period from $-2000 \mathrm{~ms}$ to $-100 \mathrm{~ms}$ before bout onset. The last $100 \mathrm{~ms}$ was excluded as some of these neurons produced premotor activity before INs. This method yielded times that were much earlier compared with the bootstrap threshold method outlined above. To assess the significance of these values, I estimated SEs using the resampling procedure outlined above. In addition, I also calculated the overall firing rate in the $1900 \mathrm{~ms}$ period from -2000 to -100 $\mathrm{ms}$ before bout onset and simulated spike trains for each bout onset assuming uniform spiking probability (number of bouts was same as original data). This procedure was repeated 10,000 times, the observed median last spike time was compared with this distribution, and a $p$-value was calculated. Using this method, 8 of the $11 \mathrm{HVC}_{\mathrm{X}}$ neurons

$\leftarrow$

(Figure legend continued.) RA. The three major types of neurons that are known to exist in HVC and the major connections between them are shown. Note: $\mathrm{HVC}_{\mathrm{Av}}$ neurons have not been shown. $\boldsymbol{B}$, Each symbol represents the sparseness index for motif-related firing and the motifrelated firing rates for all recorded neurons. Open circles $(O)$ represent neurons classified as putative interneurons, + represents neurons classified as putative $\mathrm{HVC}_{x}$ neurons, and $\Delta$ represents antidromically identified $\mathrm{HVC}_{x}$ neurons. $C$, Distribution of numbers of motif-related bursts for putative $\mathrm{HVC}_{\mathrm{x}}$ neurons $(+)$ and antidromically verified $\mathrm{HVC}_{\mathrm{x}}$ neurons $(\Delta) . \boldsymbol{D}, \boldsymbol{E}$, Example recordings from a putative $H V C_{x}$ neuron (darker + in $\boldsymbol{B}$ ) and a putative interneuron (darker $\bigcirc$ in $\boldsymbol{B}$ ). Left, Voltage trace and spectrogram for one song bout, middle-average waveform (black), and 100 randomly selected spike waveforms overlaid in gray. Right, ISI histogram generated using all recorded spikes during spontaneous activity and singing. Scale bars for the spike waveforms plot: $x$-axis, $0.5 \mathrm{~ms} ; y$-axis, $100 \mu V$. F, G, Motif-related activity of the neurons shown in $\boldsymbol{D}$ and $\boldsymbol{E}$, respectively. Top, Spectrogram of the motif of median length. Middle, Raster plot showing the spike times for the first 100 motif renditions linearly time warped to fit the timing of the median motif (see Materials and Methods for details). Bottom, Average motifrelated firing rate across all motif renditions. showed median last spike times that were significantly different from chance $(p<0.05)$ and all of these had median last spike times in the range of $800 \mathrm{~ms}$ (see Fig. $6 C$ ), further supporting the conclusion that these neurons significantly decrease their firing rate hundreds of milliseconds before song bout onset. In addition, several of the other $\mathrm{HVC}_{\mathrm{X}}$ neurons that did not show significant pre-bout activity changes also showed significant median last spike times (see Fig. 6C).

At the population level, the time course of increases and decreases in activity for interneurons and $\mathrm{HVC}_{\mathrm{X}}$ neurons was obtained by averaging the mean-subtracted firing rates of all neurons that showed significant pre-bout changes (see Fig. $6 A ; n=13$ interneurons, $n=4 \mathrm{HVC}_{\mathrm{X}}$ neurons with increased pre-bout activity and $n=12 \mathrm{HVC}_{\mathrm{X}}$ neurons with decreased pre-bout activity).

Estimation of time of first spike burst during the motif. For all $\mathrm{HVC}_{\mathrm{X}}$ neurons used in the analysis of pre-bout activity, time-warped, motifrelated, and IN-related PSTHs were calculated with $1 \mathrm{~ms}$ resolution and convolved with a Gaussian kernel $(\sigma=5 \mathrm{~ms}$, length $=3 \sigma)$. Peaks $>50 \mathrm{~Hz}$ in the convolved PSTH were considered as times when the neuron was active. Through visual examination, I verified that this procedure captured all motif-related and IN-related bursts of $\mathrm{HVC}_{\mathrm{X}}$ neurons.

Characterization of IN progression features. IN progression features were characterized as described earlier (Rajan and Doupe, 2013). Briefly, the first IN in a solitary IN bout was taken and the proportion of times it was followed by another syllable was calculated. When it was followed by another syllable, the interval to the next syllable was measured and used to determine the median interval to the next syllable. Finally, the acoustic distance to the last IN was calculated as the Mahalanobis distance of the first IN in each bout from the last IN acoustic features (duration, Wiener entropy, log amplitude, and mean frequency). All of these characteristics were also calculated for the first IN in IN song bouts.

Experimental design and statistical analysis. All statistics were performed at an $\alpha$ level of 0.05 . Sample size calculations were not done before the study. However, the number of neurons and number of trials considered for each neuron is comparable to other studies. For each bout type, only neurons with $\geq 3$ trials of that bout type were considered for further analysis.

Paired data comparisons for pre-bout activity and spontaneous activity for individual neurons was done using the Wilcoxon sign-rank test (see Figs. 3A, B, 5D; MATLAB function signrank). Unpaired comparisons of pre-bout activity and latencies across different bout types was done using a Kruskal-Wallis test followed by post hoc Tukey-Kramer test (see Figs. 4B-D, $7 A, B$; MATLAB function kruskalwallis and multcompare). The Kruskal-Wallis test was also used to compare differences in timing and acoustic structure of first INs from solitary IN bouts and IN song bouts (see Fig. 9A,B). Resampling statistics were used to calculate the significance of latency estimates for individual neurons (see Fig. $6 B, C)$. Pearson's correlation was used to test for correlation between the time at which $\mathrm{HVC}_{\mathrm{X}}$ neurons started to decrease their firing rate and the time of the first motif-related spike burst of the same neurons (see Fig. $8 A$ ).

\section{Results}

I analyzed the activity of 56 single units in HVC during the production of self-initiated (undirected) song produced when the bird was alone. HVC has at least four different neuron types: $\mathrm{HVC}_{\mathrm{RA}}$-projecting neurons, $\mathrm{HVC}_{\mathrm{X}}$-projecting neurons, $\mathrm{HVC}_{\mathrm{Av}^{-}}$ projecting neurons, and interneurons (Fig. 1A; Dutar et al., 1998; Hahnloser et al., 2002; Mooney and Prather, 2005; Kozhevnikov and Fee, 2007; Long et al., 2010; Kosche et al., 2015; Roberts et al., 2017). Similar to previous studies (Swadlow, 1998; Hahnloser et al., 2002; Kozhevnikov and Fee, 2007), 13 single units were classified as $\mathrm{HVC}_{\mathrm{X}}$-projecting neurons using antidromic identification methods (see Materials and Methods); the rest of the units were classified as putative interneurons $(n=17)$ and putative $\mathrm{HVC}_{\mathrm{X}}$-projecting neurons $(n=26)$ based on comparison of spontaneous (nonsinging) activity and motif-related activity to earlier studies (Hahnloser and Fee, 2007; Kozhevnikov and Fee, 
A
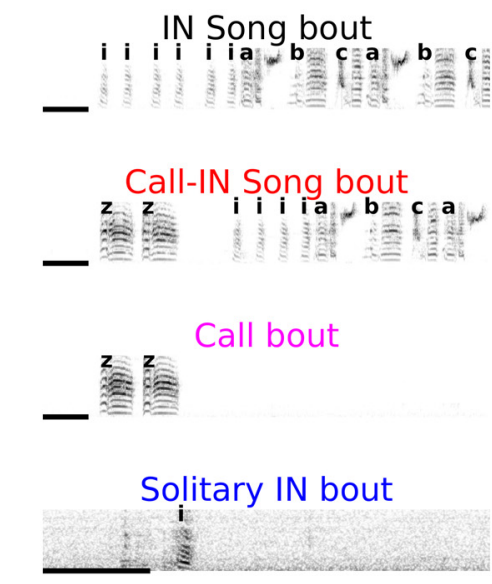

B
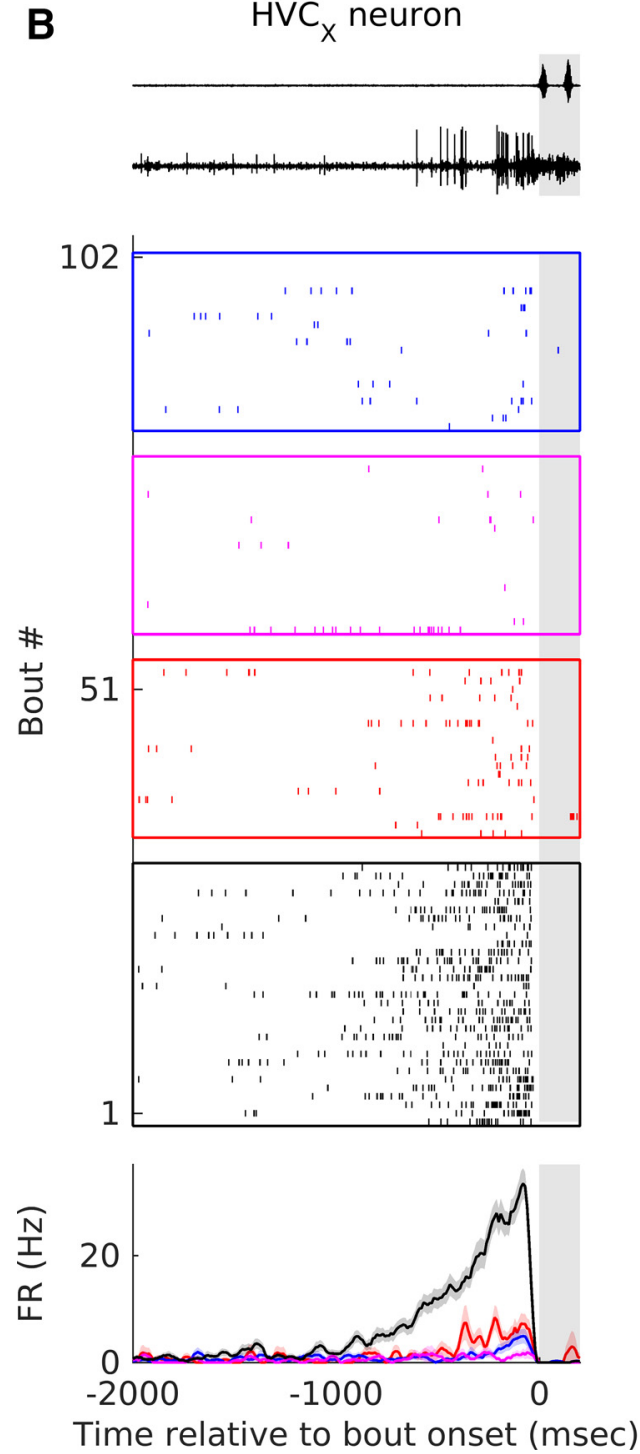

C
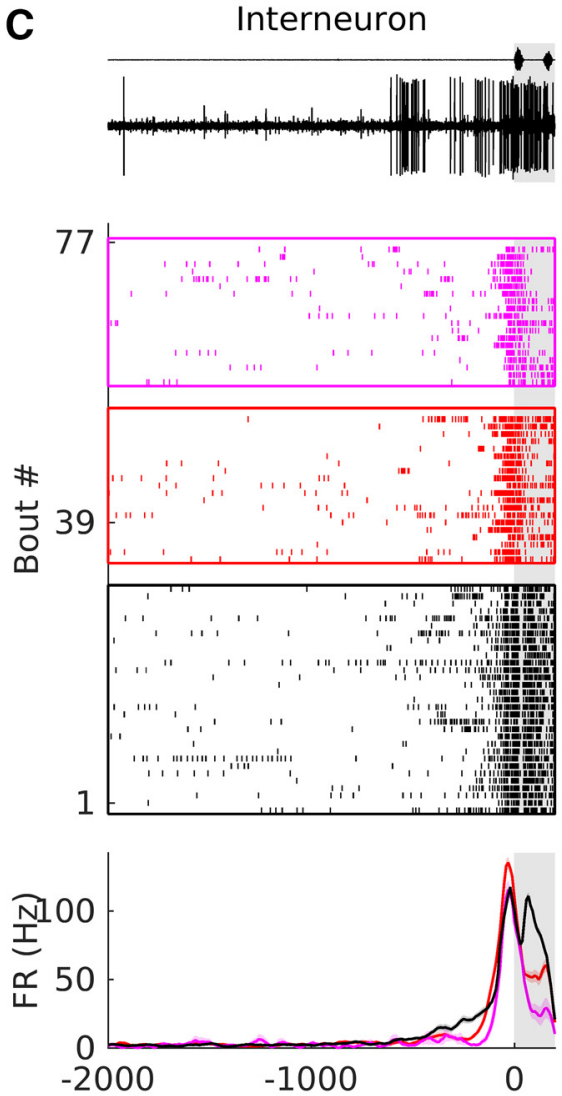

Time relative to bout onset $(\mathrm{msec})$

D

HVC $_{x}$ neuron
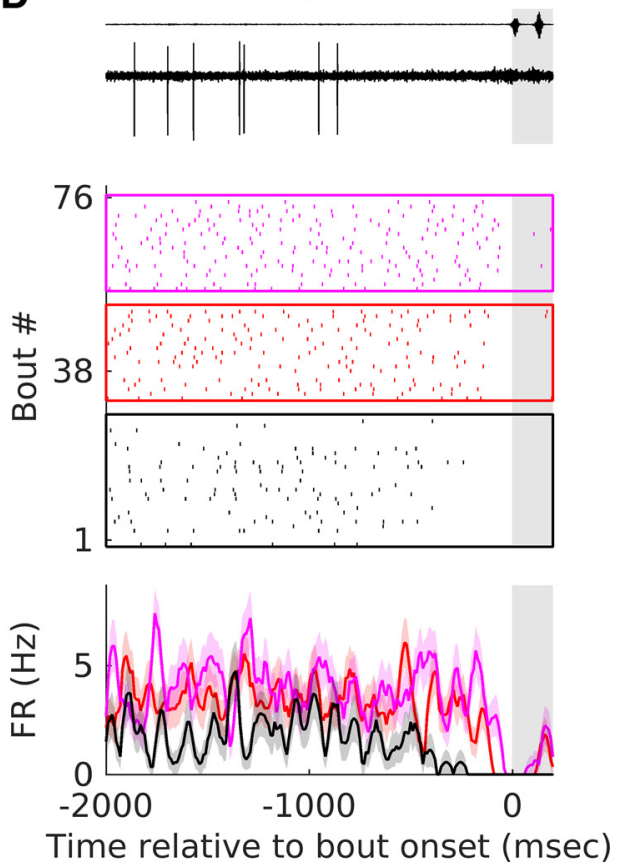

Figure 2. Bout types and examples of pre-bout activity in interneurons and $H V C_{X}$-projecting neurons. $A$, Example spectrograms of the four bout types considered in this study. INs are represented with "i"; ; motif syllables are represented by the letters "a," "b," and "c," and calls are represented by the letter " $z$." $\boldsymbol{B}-\boldsymbol{D}$, Examples of activity of an interneuron $(\boldsymbol{C})$ and two HVC $\boldsymbol{C}_{x}$ neurons $(\boldsymbol{B}, \boldsymbol{D})$ before the onset of the different types of bouts. Top, Example of sound waveform recorded on the microphone and voltage trace from recording electrode starting $2000 \mathrm{~ms}$ before bout onset and ending $200 \mathrm{~ms}$ after bout onset for one IN song bout. Middle, Raster plot showing the activity of the neuron before the different bout types. In all cases, rasters are aligned on the onset of the first vocalization of the bout. The different colors represent different bout types-black for IN song bouts, red for call-IN song bouts, magenta for call bouts and blue for solitary IN bouts. The number of bouts plotted is restricted to 30 for IN song bouts and 20 for other bout types. Bottom, PSTH showing average firing rate relative to the onset of different bout types. Color code is same as that used for the raster. Shaded portion in all plots represents the $200 \mathrm{~ms}$ after bout onset. Shading represents SEM. 

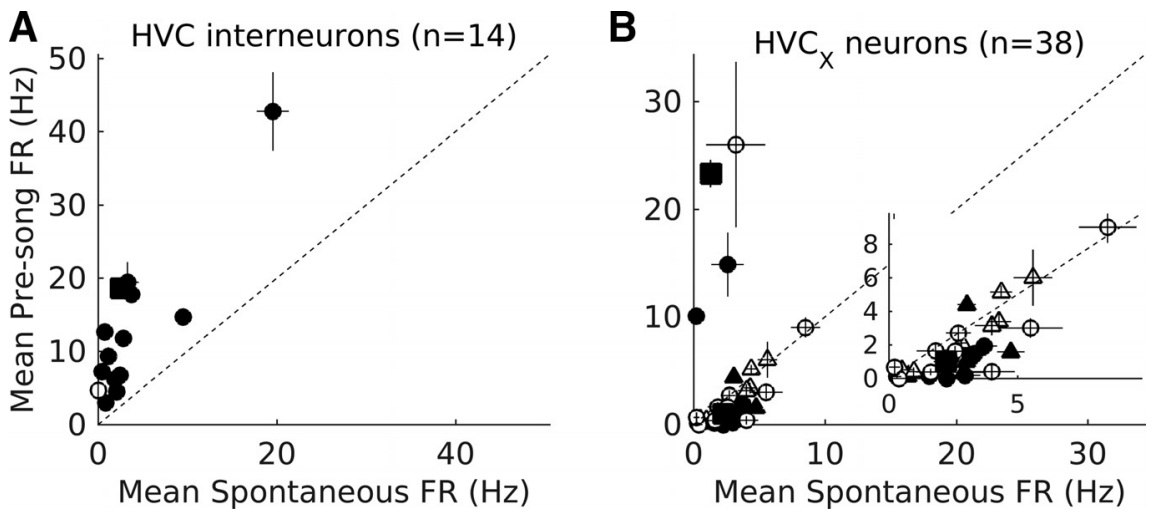

Figure 3. Interneurons and $\mathrm{HVC}_{x}$ neurons change their activity before song bout onset. $A, B$, Comparison of spontaneous firing rates ( -2000 to $-500 \mathrm{~ms}$ before bout onset) with pre-bout firing rates $(-600$ to $-100 \mathrm{~ms}$ before bout onset) for interneurons $(n=14 ; A)$ and $H_{V C}$ neurons ( $n=25$ putative HVC neurons represented by circles and $n=13$ antidromically identified HVC neurons represented by triangles; $\boldsymbol{B}$ ). Each symbol represents mean firing rate and the whiskers represent SEM. Filled symbols represent neurons that showed significant differences in pre-bout activity $(p<0.05$, Wilcoxon signed-rank test). Dotted line represents equal spontaneous and pre-bout activity. Square above the dotted line in $A$ represents the interneuron shown in Figure 2C. Squares above and below the dotted line in $\boldsymbol{B}$ represent $\mathrm{HVC}_{x}$ neurons shown in Figure $2 B$ and $D$, respectively. Inset in $\boldsymbol{B}$ shows an enlarged view of the lower left corner to highlight $\mathrm{HVC}_{\mathrm{X}}$ neurons that showed pre-bout decreases in activity.

2007; Fig. 1B, see Materials and Methods for details). As described earlier (Hahnloser et al., 2002; Kozhevnikov and Fee, 2007), putative interneurons had high motif-related activity and were active throughout the motif (Fig. $1 B, E, G$ ). Putative and antidromically identified $\mathrm{HVC}_{\mathrm{X}}$ neurons had low motif-related activity (Fig. $1 B$ ) and produced $0-5$ discrete bursts during the motif (Fig. $1 B, C, D, F$ ). Putative $\mathrm{HVC}_{\mathrm{X}}$-projecting neurons and antidromically identified $\mathrm{HVC}_{\mathrm{X}}$-projecting neurons showed similar properties (Fig. $1 B, C$ ) so they were combined and are referred to as $\mathrm{HVC}_{\mathrm{X}}$ neurons. Putative interneurons are referred to as interneurons. Motif-related activity and IN-related activity of 49 of these neurons has been described previously (Rajan and Doupe, 2013; Woolley et al., 2014; see Materials and Methods section: details of overlap with previous studies).

\section{HVC interneurons and $\mathrm{HVC}_{\mathrm{X}}$ neurons changed their activity before bout onset}

The primary objective of this study was to determine whether preparatory activity, characterized by longer timescale changes in neural activity, was present in HVC, specifically before the onset of song bouts. Previous studies have shown the presence of stereotyped patterns of activity starting $\sim 50 \mathrm{~ms}$ before the onset of INs and song syllables (McCasland, 1987; Hahnloser et al., 2002; Schmidt, 2003; Rajan and Doupe, 2013). In this study, I extended these results to quantify changes in neural activity well before this $50 \mathrm{~ms}$ premotor window.

To quantify preparatory activity and its specificity, I segregated groups of vocalizations into 4 types of bouts based on two criteria: (1) presence of song syllables and (2) whether the first syllable of the bout was an IN (Fig. 2A, see Materials and Methods). For each bout type, a neuron was included if it was recorded for $\geq 3$ bouts of that type. Figure $2 B-D$, illustrates changes in an HVC interneuron (Fig. $2 C$ ) and $2 \mathrm{HVC}_{\mathrm{X}}$ neurons (Fig. $2 \mathrm{~B}, \mathrm{D}$ ) before the different types of bouts. To quantify changes in individual neurons, spontaneous activity, measured from -2000 to -1500 ms before bout onset was compared with pre-bout activity measured from -600 to $-100 \mathrm{~ms}$ before bout onset. The last $100 \mathrm{~ms}$ was excluded from the analysis as this has been shown to represent premotor activity related to the upcoming syllable (McCasland, 1987; Yu and Margoliash, 1996; Margoliash, 1997;
Schmidt, 2003; Rajan and Doupe, 2013). Overall, 56\% (29/52) of the neurons showed significant changes in pre-bout activity before the onset of IN song bouts (Fig. $3 A, B ; p<0.05$, Wilcoxon sign-rank test). In total, $92.86 \%$ of interneurons (Fig. $3 A, n=13 / 14$ ) and $10.53 \%$ of $\mathrm{HVC}_{\mathrm{X}}$ neurons (Fig. $3 B, 4 / 38 ; n=3 / 25$ putative and $n=1 / 13$ antidromically identified) increased their activity, whereas $31.58 \%$ of $\mathrm{HVC}_{\mathrm{X}}$ neurons (Fig. 3B, 12/38; $n=$ $8 / 25$ putative and $n=4 / 13$ antidromically identified) decreased their activity before onset of the first IN of IN song bouts.

\section{Pre-bout activity changes occurred specifically before the first IN in IN song bouts and call-IN song bouts} To determine whether such changes were specific to IN song bouts, I used the same procedure to quantify changes in activity before the onset of other bout types. A greater proportion of interneurons and $\mathrm{HVC}_{\mathrm{X}}$ neurons showed significant changes in activity specifically before IN song bouts (Fig. 4A). For neurons that increased their firing rate before bout onset, changes in activity were greater specifically before IN song bouts (Fig. $4 B, D$ ). However, due to small sample sizes and adjustments for multiple comparisons, some of these differences were not statistically significant (Fig. $4 B, D) . H_{\mathrm{X}}$ neurons that decreased their activity before bout onset also showed greater decreases specifically before IN song bouts (Fig. 4C). These results suggested that such changes in activity before the first IN were important for successful progression to song.

To further test this, I examined call-IN song bouts, where the initial call was followed by INs and song. In these bouts, the interval between the last call and the first IN was highly variable $($ mean $\pm \mathrm{SEM}=544.31 \pm 74.93 \mathrm{~ms}$; mean $\pm \mathrm{SEM}$ of $\mathrm{CV}=$ $0.712 \pm 0.04 ; n=6$ birds), suggesting that the first IN in call-IN song bouts occurs independent of the initial call. Therefore, after the initial call, call-IN song bouts would become similar to IN song bouts. If this were the case, I would have expected levels of activity before the first IN of call-IN song bouts to be similar to the levels of activity before the first IN of an IN song bout. Consistent with this prediction, both the proportion of neurons showing significant changes in activity and the magnitude of changes before the first IN of a call-IN song bout were similar to changes seen before the first IN of an IN song bout (Fig. 4A-D). Together with the absence of activity changes before calls and solitary IN bouts, these results strengthened the conclusion that pre-bout activity changes occurred specifically before the first IN of IN song bouts and suggested their importance for successful song initiation.

Neurons outside HVC showed no pre-bout changes in activity Increases in activity before song bouts have also been shown to occur in two song control areas downstream to $\mathrm{HVC}_{\mathrm{X}}$-projecting neurons: Area X (Hessler and Doupe, 1999; Woolley et al., 2014) and lateral magnocellular nucleus of the anterior neostriatum (LMAN) (Hessler and Doupe, 1999; Kao et al., 2008). To determine whether the changes described above were specific to neurons within song control area HVC, I also recorded and analyzed the activity of neurons that were outside of HVC just before the 

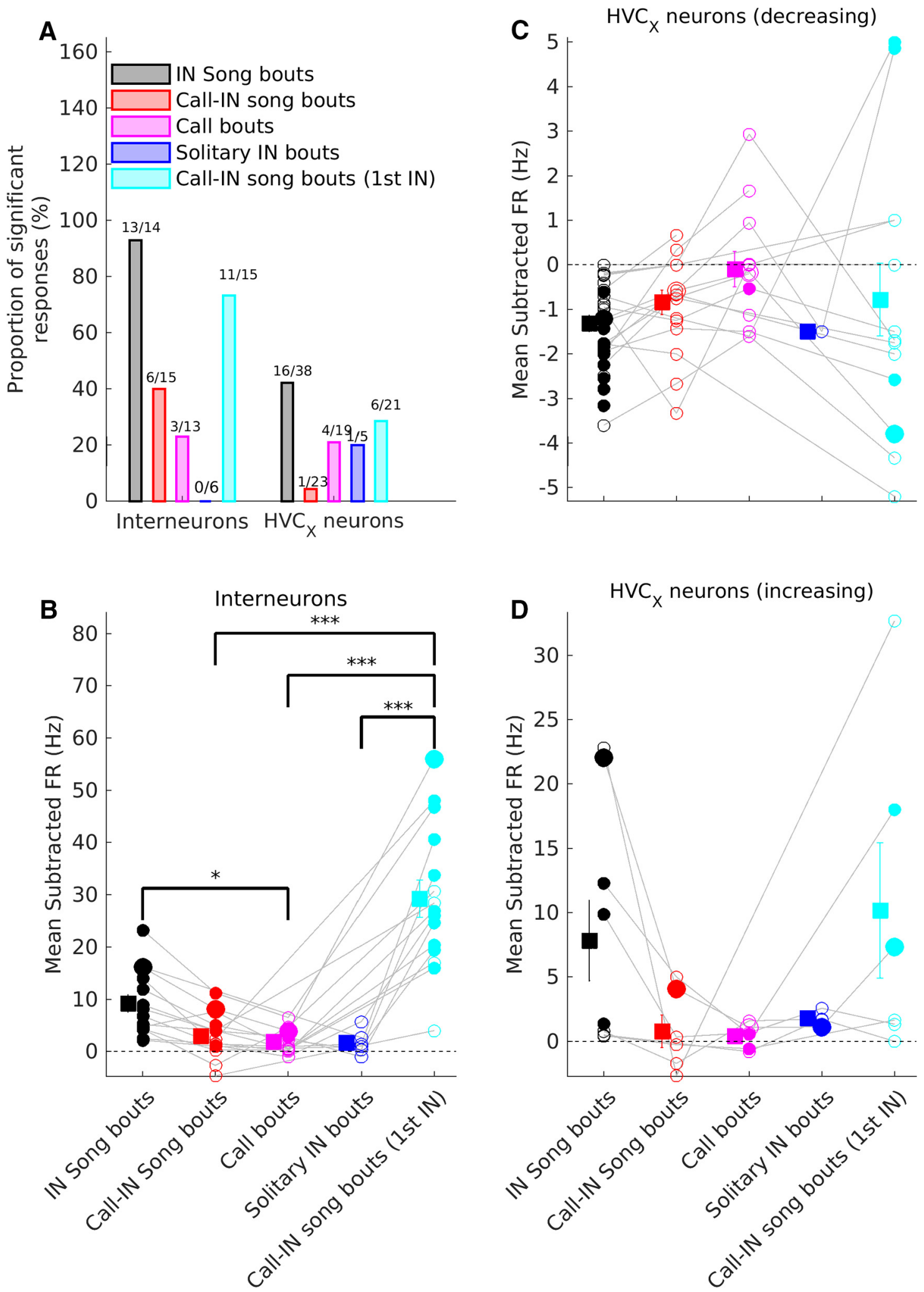

Figure 4. Activity changes before IN song bouts are larger and more common. $A$, Comparison of the proportion of neurons with significant pre-bout changes in activity for the different bout types. Data are plotted separately for interneurons and $H_{V} C_{x}$ neurons. Numbers above each bar indicate the number of neurons with significant changes and the total number of neurons for that bout type. $\boldsymbol{B}-\boldsymbol{D}$, Comparison of mean subtracted pre-bout firing rate for interneurons $(\boldsymbol{B}), \mathrm{HV} \mathrm{C}_{\mathrm{x}}$ neurons with decreasing pre-bout activity $(\boldsymbol{C})$, and $\mathrm{HVC}_{\mathrm{X}}$ neurons with increasing pre-bout activity $(\boldsymbol{D})$. Circles represent individual neurons. Gray lines connect data from the same neuron recorded during multiple bout types. Squares and whiskers represent means and SEM for each bout type. Filled circles represent neurons with significant changes in pre-bout firing rate for a given bout type. Larger symbols represent the neurons shown in Figure $2, B-D .{ }^{*}$ and ${ }^{* * *}$ represent significant differences between groups (Kruskal-Wallis test followed by post hoc Tukey-Kramer test). ${ }^{*} p<0.05,{ }^{* * *} p<0.001$, post hoc test. $\boldsymbol{B}$, Kruskal-Wallis $p=3.7^{*} 10^{-6}$. C, Kruskal-Wallis $p=0.1353$. D, Kruskal-Wallis $p=0.0996$. In all panels, black represents IN song bouts, red represents call-IN song bouts, magenta represents call bouts, blue represents solitary IN bouts, and cyan represents pre-bout activity before the first IN of call-IN song bouts. 
A

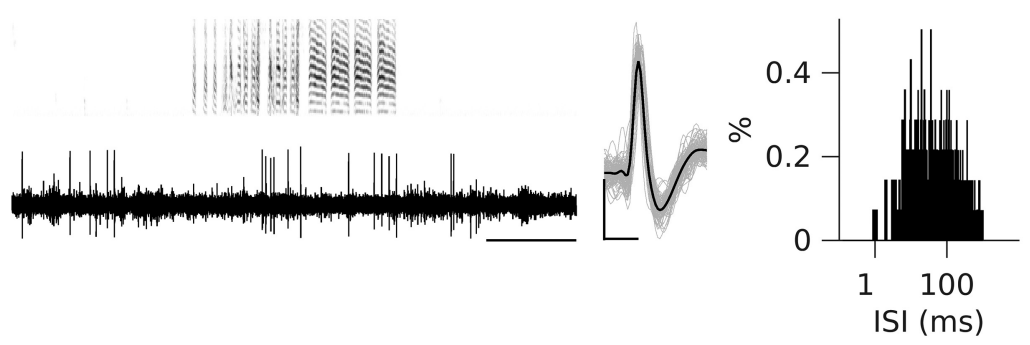

B

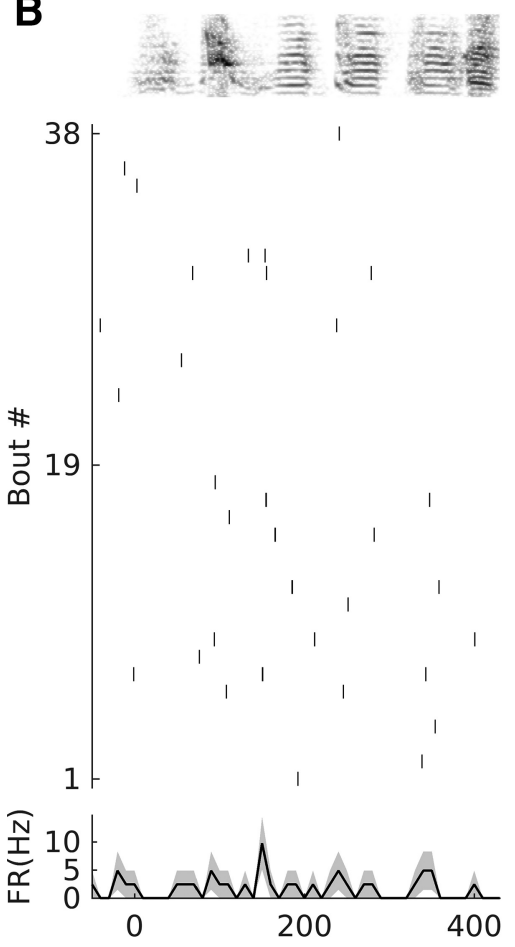

Time relative to onset of motif (msec)
C
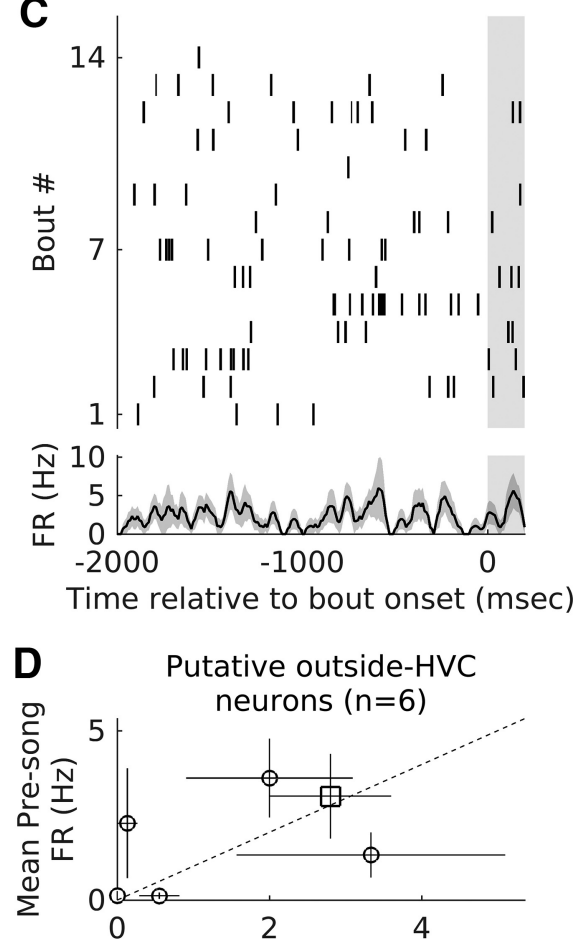

Mean Spontaneous FR (Hz)

Figure 5. Putative outside HVC neurons do not show significant pre-bout activity changes. $A$, Example recordings from a putative outside-HVC neuron. Left, Voltage trace and spectrogram for one IN song bout. Middle, Average waveform (black) and 100 randomly selected spike waveforms overlaid in gray. Right, ISI histogram generated using all recorded spikes during spontaneous activity and singing. Scale bars for the spike waveforms plot: $x$-axis, $0.5 \mathrm{~ms} ; y$-axis, $100 \mu \mathrm{V}$. $\boldsymbol{B}$, Motif-related activity of the neuron shown in $\boldsymbol{A}$. Top, Spectrogram of the motif of median length. Middle, Raster plot showing the spike times for all motif renditions linearly time-warped to fit the timing of the median motif (see Materials and Methods for details). Bottom, Average motif-related firing rate across all motif renditions. Shading represents SEM. C, Pre-bout activity of the outside-HVC neuron shown in $\boldsymbol{A}$. Top, Raster plot showing the activity of the neuron before the onset of multiple IN song bouts aligned to the onset of the first IN. Bottom, PSTH showing average firing rate relative to the onset of IN song bouts. Shading represents SEM. D, Comparison of spontaneous firing rates ( -2000 to $-1500 \mathrm{~ms}$ before bout onset) with pre-bout firing rates ( -600 to $-100 \mathrm{~ms}$ before bout onset) for all outside HVC neurons $(n=6)$. Each symbol represents mean firing rate and the whiskers represent SEM. Unfilled symbols represent neurons that did not show significant differences ( $p \geq 0.05$, Wilcoxon signed-rank test). Dotted line represents equal spontaneous and pre-bout activity. Square represents the neuron shown in $\boldsymbol{A}$ and $\boldsymbol{B}$.

onset of IN song bouts (Fig. 5, $n=6$; see Materials and Methods for description of such neurons; median number of IN song bouts per neuron $=15$; range $=3-47$ ). These neurons did not have stereotyped motif-related activity (Fig. $5 A, B$ ). These neurons also showed no change in activity before the onset of IN song bouts (Fig. 5C,D, $p>0.05$, Wilcoxon sign-rank test). This proportion of nonresponsive neurons was different from the proportion of HVC neurons that showed significant changes before song bout onset ( $56 \%$ within HVC vs $0 \%$ outside of HVC; $p=$ $0.0097, \chi^{2}$ test). These data suggested that changes in neural activity before the onset of IN song bouts are restricted to neurons in song control areas.
HVC neurons changed their activity $\sim 200-800 \mathrm{~ms}$ before song bout onset The analysis described above showed that $56 \%$ of HVC neurons changed their activity in a $500 \mathrm{~ms}$ window before song bout onset, but the exact time when activity changed was unclear. Figure $6 \mathrm{~A}$ shows population average activity for the different types of changes that were observed: (1) interneurons that increased their activity $(n=13),(2) \mathrm{HVC}_{\mathrm{X}}$ neurons that increased their activity $(n=4)$, and (3) $\mathrm{HVC}_{\mathrm{X}}$ neurons that decreased their activity $(n=12)$. As a population, all three types of changes were apparent hundreds of milliseconds before the onset of the first IN of an IN song bout. At the individual neuron level, $\mathrm{HVC}_{\mathrm{X}}$ neurons that increased their activity changed first (Fig. $6 B$, mean \pm SEM: $-616.8 \pm 170.9 \mathrm{~ms}$; range: -928 to -129 $\mathrm{ms}$ relative to song bout onset), followed by interneurons (Fig. 6B, mean \pm SEM: $-417 \pm 46.8 \mathrm{~ms}$; range: -674 to $-117 \mathrm{~ms}$ ), followed by $\mathrm{HVC}_{\mathrm{X}}$ neurons that decreased their activity (Fig. 6B, mean \pm SEM: $-201 \pm 58.7 \mathrm{~ms}$; range: -528 to $-47 \mathrm{~ms}$ ). Decreases in the activity of $\mathrm{HVC}_{\mathrm{X}}$ neurons estimated using the median time of occurrence of the last spike before bout onset (see Materials and Methods) suggested an earlier time for change (Fig. $6 C, \sim 600-1300 \mathrm{~ms}$ before bout onset), albeit with larger error estimates.

Consistent with changes in activity being specific for IN song bouts, I found that changes in activity occurred earlier before IN song bouts (Fig. $7 A, B$ ). Overall, these data show that neurons within HVC changed their activity hundreds of milliseconds before the onset of the first IN of an IN song bout, suggesting that these changes represent preparatory activity before the start of an IN song bout. The absence of such changes before solitary INs suggested that these changes were not related to the first IN alone, but were more generally important for successful song initiation. A recent study also showed similar increases in HVC activity before song bout onset in HVC projection neurons in juvenile zebra finches (Okubo et al., 2015).

Pre-bout activity changes are not related to times of motifrelated activity in $\mathrm{HVC}_{\mathrm{X}}$ neurons

Similar premovement changes in activity have been described in earlier studies in primates (Tanji and Evarts, 1976; Riehle and Requin, 1989; Churchland et al., 2006, 2010). These changes were thought to represent subthreshold movement activity because individual neurons showed similar premovement- and movementrelated activity. (Tanji and Evarts, 1976; Riehle and Requin, 1989). However, more recent studies have shown that this similarity is not present in all neurons (Churchland et al., 2010) and 

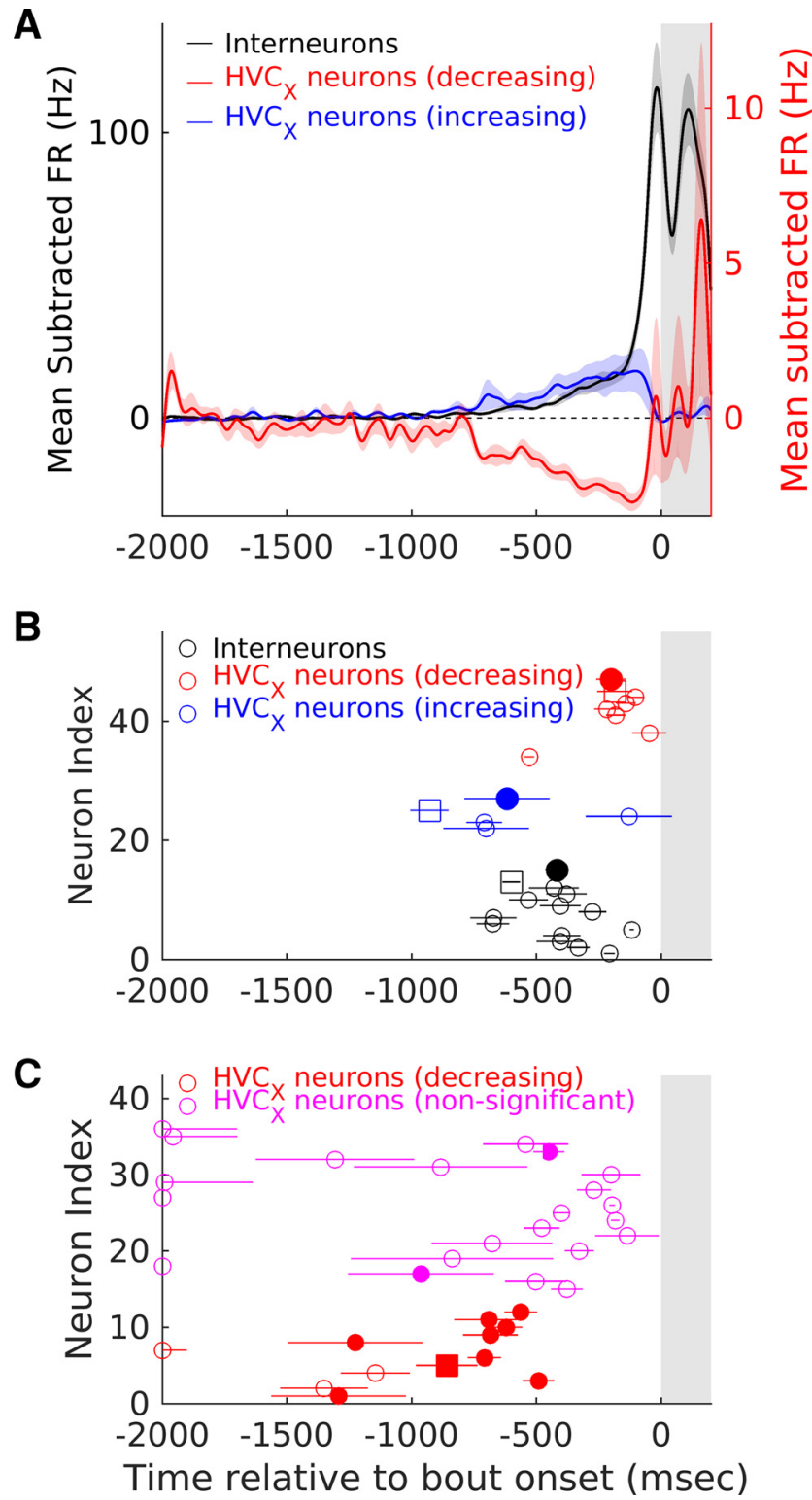

Figure 6. Interneurons and $\mathrm{HVC}_{\mathrm{X}}$-projecting neurons change their firing rate $\sim 217-775 \mathrm{~ms}$ before song bout onset. $A$, Population average mean-subtracted activity for the three types of changes seen before the onset of IN song bouts. Black line represents interneurons that significantly increased their activity ( $n=13$, see Materials and Methods). Blue line represents $\mathrm{HVC}_{\mathrm{X}}$ neurons that significantly increased their activity $(n=4)$ and red line represents $\mathrm{HVC}_{x}$ neurons that significantly decreased their activity $(n=12)$. In all cases, activity is aligned to the onset of the first IN at time $t=0$. Shading represents SEM. $\boldsymbol{B}$, Latency of change for individual neurons is shown. Unfilled circles represent individual neurons with whiskers representing SE estimates (see Materials and Methods for details of estimation procedure). Filled circles represent means for each of the groups and whiskers represent SEM. Black symbols represent interneurons, blue symbols represent $\mathrm{HVC}_{X}$ neurons that show increases, and red symbols represent $\mathrm{HVC}_{x}$ neurons that show decreases. Unfilled squares in each category show the changes for the example neurons shown in Figure $2, B-D$. C, Latency of change for individual $H V C_{x}$ neurons calculated as the median time of occurrence of the last spike in each IN song bout across all IN song bouts. Circles represent individual neurons with whiskers representing SE estimates (see Materials and Methods for details of estimation procedure). Filled circles represent cases in which the latency was significantly different from chance (see Materials and Methods for details of significance calculations). Red symbols represent $\mathrm{HVC}_{\mathrm{x}}$ neurons that showed decreases and magenta symbols represent $H V C_{x}$ neurons that did not show significant pre-bout changes in activity. Red, filled square represents the example neuron shown in Figure 1D. Shaded portion in all panels represents the $200 \mathrm{~ms}$ after bout onset. have suggested that premovement activity reflects the dynamics of motor preparation (Churchland et al., 2010; Shenoy et al., 2013). To understand the relationship between pre-bout activity and singing-related activity in HVC neurons, I examined motifrelated activity of $\mathrm{HVC}_{\mathrm{X}}$ neurons that showed significant prebout activity changes. I focused on $\mathrm{HVC}_{\mathrm{X}}$ neurons because they are active only at a few discrete times during the song motif (and/or during INs; Hahnloser et al., 2002; Kozhevnikov and Fee, 2007; Rajan and Doupe, 2013; Woolley et al., 2014), making it possible to precisely examine the relation, if any, between prebout activity and song- (or IN)-related activity.

None of the $\mathrm{HVC}_{\mathrm{X}}$ neurons that showed pre-bout increases in activity were active during song and only one of them was active during INs $(n=1 / 4)$, suggesting a specific role for such neurons in motor preparation. All of the $\mathrm{HVC}_{\mathrm{X}}$ neurons that showed pre-bout decreases in activity were active during song $(n=12)$ and two of them were also active during INs. Further, the time at which pre-bout activity started to decrease in these $\mathrm{HVC}_{\mathrm{X}}$ neurons (quantified using the median time of last spike) was not correlated with the time at which these neurons produced their first spike burst during the song motif (Fig. $8 A, r=0.27, p=0.40$, Pearson's correlation). These results highlighted a novel role for HVC neurons in motor preparation and suggested that pre-bout activity changes are not directly related to singing-related activity, but rather reflect the dynamics of motor preparation.

Solitary INs are different from the first IN of an IN song bout The lack of preparatory activity before solitary INs suggested the importance of preparatory activity in HVC for successful song initiation. To determine whether the absence of preparatory activity influenced the properties of solitary INs, I next compared the timing and acoustic structure of the first IN between solitary IN bouts and IN song bouts. Timing and acoustic structure were chosen because both of these properties are thought to be important for the progression of INs to song (Rajan and Doupe, 2013).

To examine the properties of solitary IN bouts, I recorded and labeled songs from nine additional birds (in addition to two of the birds used for single unit recording). To maximize chances of obtaining solitary IN bouts, I recorded vocalizations continuously for periods of 4-6h (see Materials and Methods for recording procedures). However, only seven birds (two of the birds used for single unit recording and five additional birds) produced solitary IN bouts and these were considered for further analysis. The first IN in a solitary IN bout was followed by another syllable in $21.14 \%$ of bouts (proportion of bouts in which another syllable followed the first IN $=0,0.35,0.1,0.48,0,0$, and 0.55 for the 7 birds). In $75 \%$ of birds (3/4), the interval to the next syllable (whenever there was a second syllable) was significantly longer in the case of solitary IN bouts compared with IN song bouts (Fig. $9 A, p<0.05$, Kruskal-Wallis test). Further, in $57.14 \%$ of the birds (4/7), the first IN in a solitary IN bout had significantly greater acoustic distance from the last IN compared with the first IN in an IN song bout (Fig. 9B, $p<0.05$, Kruskal-Wallis test). Therefore, when compared with the first IN in an IN song bout, the first IN in a solitary IN bout was further away from the last IN both in terms of timing and acoustic structure. These results suggested that pre-bout preparatory activity contributes to successful song initiation by altering the properties of the first IN, thereby influencing progression of IN sequences toward song sequence production. 

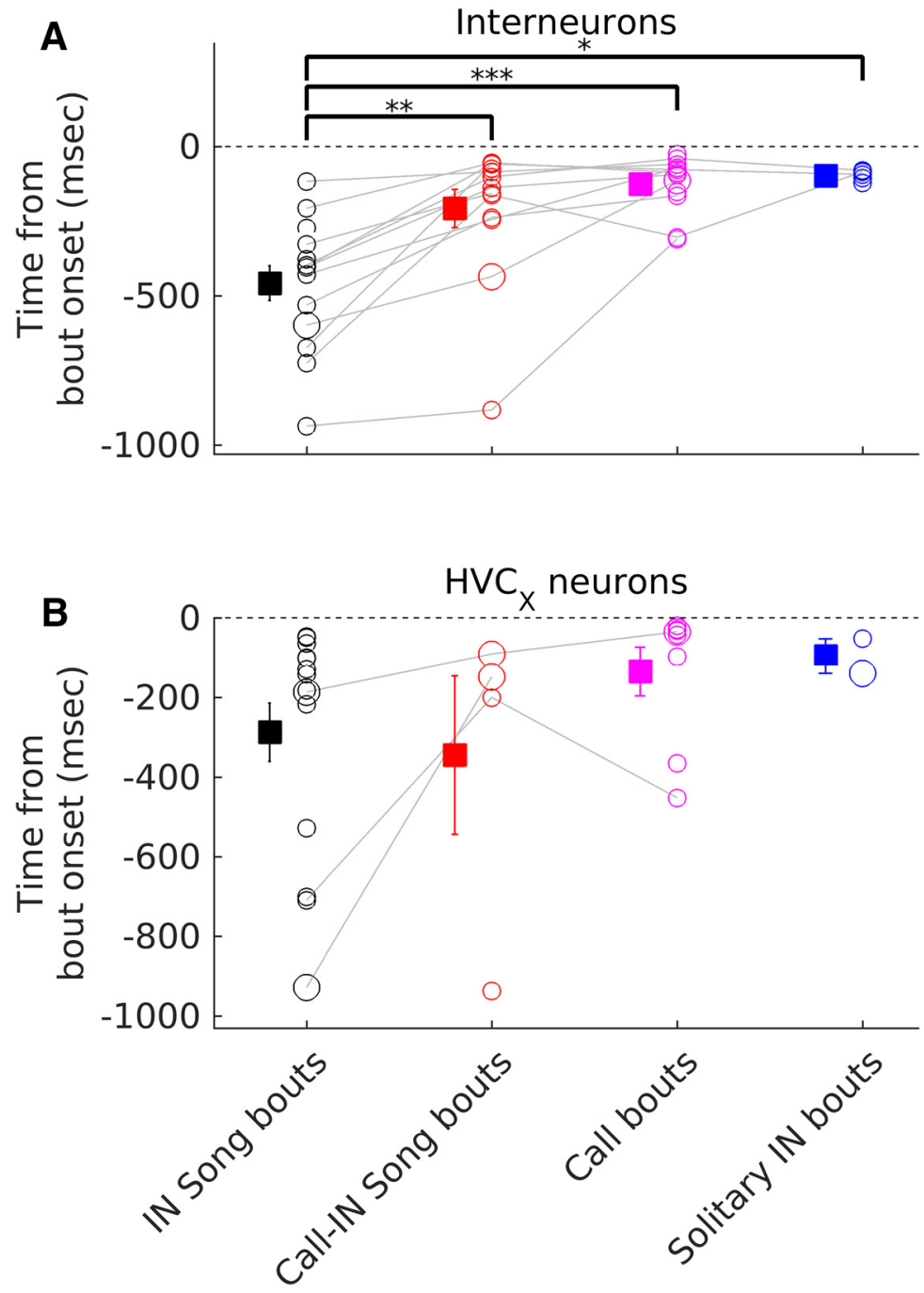

Figure 7. Pre-bout activity changes occur earlier before IN song bouts. $A, B$, Comparison of latency of pre-bout firing rate changes across different bout types for interneurons $(\boldsymbol{A})$ and $\mathrm{HVC}_{x}$ neurons $(\boldsymbol{B})$. Circles represent individual neurons. Gray lines connect data from the same neuron recorded during multiple bout types. Squares and whiskers represent means and SEM for each bout type (black for IN song bouts, red for call-IN song bouts, magenta for call bouts, blue for solitary IN bouts). Larger symbols represent the neurons shown in Figure 2, $B-D .{ }^{*},{ }^{* *}$ and ${ }^{* * *}$ represent significant differences between groups (Kruskal-Wallis test followed by post hoc Tukey-Kramer test). ${ }^{*}$ Post hoc test $p<0.05,{ }^{* *} p<0.01,{ }^{* * *} p<0.001 . A$, Kruskal-Wallis $p=1.95^{*} 10^{-4}$. B, Kruskal-Wallis $p=0.095$.

\section{Discussion}

Here, I show that two types of neurons in premotor nucleus HVC changed their activity significantly several hundreds of milliseconds before the onset of song bouts (Figs. 2, 6). While interneurons increased their activity, basal-ganglia-projecting $\mathrm{HVC}_{\mathrm{X}}$ neurons either increased or decreased their activity (Fig. 3). These changes were larger and more common specifically before the first IN of IN song bouts (Figs. 4, 7). Further, such changes were not present when INs were not followed by song (solitary IN bouts), suggesting their importance for song initiation (Figs. 4, 7). Finally, a small fraction of $\mathrm{HVC}_{\mathrm{X}}$ neurons that showed prebout increases in activity were not active during song or INs, suggesting a specific preparatory role for such neurons. Overall, these data demonstrated the presence of pre-bout activity changes in HVC neurons that correlated with successful song sequence initiation and suggested that pre-bout activity reflects preparatory activity important for learned movement sequence initiation.

\section{Origins of pre-bout activity}

What might drive changes in activity well before the onset of the first IN of a song bout? HVC receives major inputs from thalamic nucleus Uva (uvaeform nucleus of the thalamus), sensorimotor nucleus NIf (nucleus interfacialis), mMAN (medial magnocellular nucleus of the anterior nidopallium), and auditory nucleus Av (nucleus Avalanche; Nottebohm et al., 1982; Fortune and Margoliash, 1995; Akutagawa and Konishi, 2010; Roberts et al., 2017). Previous recordings of singing-related activity in Uva (Williams and Vicario, 1993; Danish et al., 2017), NIf (Lewandowski and Schmidt, 2011; Vyssotski et al., 2016), and Av (Roberts et al., 2017) have all shown that neurons in these areas are active immediately before the start of the first IN. However, whether these neurons have preparatory changes in activity hundreds of milliseconds before the first IN, as shown for HVC neurons in this study, remains to be determined.

In the current study, it was observed that the absence of pre-bout changes in HVC neurons correlated with INs that did not proceed to song. Previous studies have shown that inactivation of NIf makes zebra finches occasionally produce long strings of INs that do not proceed to song (Naie and Hahnloser, 2011). Further, inactivation of NIf in the anesthetized zebra finch reduces spontaneous activity and abolishes spontaneous bursts in HVC neurons (Cardin and Schmidt, 2004; Hahnloser and Fee, 2007). Together, these data suggest the possibility that NIf could be one source of pre-bout activity. However, given that most bouts after NIf inactivation still contain INs followed by song sequences (Naie and Hahnloser, 2011), NIf cannot be the only source. Pre-bout changes could also be driven by other areas such as Uva or mMAN. Previous studies have shown that birds with bilateral lesions of Uva do not produce normal song sequences (Williams and Vicario, 1993; Coleman and Vu, 2005; Danish et al., 2017). Therefore, given Uva's requirement for normal song production, it is not clear whether Uva is also involved in driving pre-bout activity in HVC.

One other possible source of pre-bout activity is the presence of calls (non-song vocalizations) produced in close proximity to the first IN. Calls are driven by areas outside of HVC because lesions of HVC do not abolish the production of calls (Simpson and Vicario, 1990). Further, HVC is active during calls (Fig. 2C; note that the interneuron is active just before call onset; Hahnloser et al., 2002; Kozhevnikov and Fee, 2007), so it is possible that this activity during calls can function similar to pre-bout activity. Consistent with this idea, I found similar levels of pre-bout activity before the first IN of call-IN song bouts and IN song bouts (Fig. 4).

Finally, previous studies have shown that neural activity gradually increases in Area X (Hessler and Doupe, 1999; Woolley et 
al., 2014) and LMAN (Hessler and Doupe, 1999; Kao et al., 2008) before the onset of undirected song bouts. The timescales of these changes was similar to the timescales of changes observed in HVC neurons in this study. Given that Area X and LMAN are downstream of $\mathrm{HVC}$, it is possible that HVC is the source of changes in Area X and LMAN. However, a recent study showed that pre-bout changes in activity in LMAN persist in the absence of Area X (Kojima et al., 2013), suggesting that changes in LMAN do not originate in HVC. Further recordings in other song system nuclei and areas upstream of LMAN will be required to identify the origin of preparatory (pre-bout) activity.

\section{Network level origins of pre-bout activity in the different subpopulations of HVC neurons}

In the current study, $92.86 \%$ of HVC interneurons $(n=13 / 14)$ increased their activity before onset of the first IN of a song bout. In previous slice recordings (Mooney and Prather, 2005; Kosche et al.,

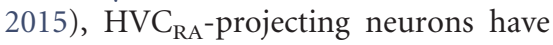
been demonstrated to be a primary source of excitatory input to interneurons. In the current study and in previous studies, pre-bout activity of $\mathrm{HVC}_{\mathrm{RA}}$-projecting neurons has not been characterized. However, it has been reported that a fraction of $\mathrm{HVC}_{\mathrm{RA}}$-projecting neurons do not have any motif-related activity (Hahnloser et al., 2002; Kozhevnikov and Fee, 2007; Long et al., 2010). Whether such neurons have pre-bout activity needs to be determined by recording from $\mathrm{HVC}_{\mathrm{RA}}$-projecting neurons before bout onset. Given the high connection probability between $\mathrm{HVC}_{\mathrm{RA}}$-projecting neurons and interneurons (Kosche et al., 2015), it is possible that a small number of $\mathrm{HVC}_{\mathrm{RA}}$ neurons with increased pre-bout activity can drive increases in a large fraction of interneurons, as seen in this study. In addition, slice recordings have shown that $\mathrm{HVC}_{\mathrm{X}}$-projecting neurons are also a source of excitatory input to interneurons, albeit less frequently than $\mathrm{HVC}_{\mathrm{RA}}$-projecting neurons (Mooney and Prather, 2005). They could also be a source of the increased pre-bout activity seen in interneurons because the timescales of increases in activity were similar for $\mathrm{HVC}_{\mathrm{X}}$ neurons and interneurons (Fig. 6).

A small fraction of $\mathrm{HVC}_{\mathrm{X}}$ neurons increased their activity before IN song bouts $(n=4 / 38$, Figs. $2 B, 3 B)$ and this activity closely resembled the slow "ramping up" described in neurons in the rat and primate brain before movement onset (Romo and Schultz, 1987; Schultz and Romo, 1992; Lee and Assad, 2003; Churchland et al., 2006, 2010; Maimon and Assad, 2006; Jin and Costa, 2010, 2015; Shenoy et al., 2013; Li et al., 2015, 2016; Chen et al., 2017). A total of $75 \%$ of these cells (3/4) were not active during song or INs, suggesting a specialized preparatory role for

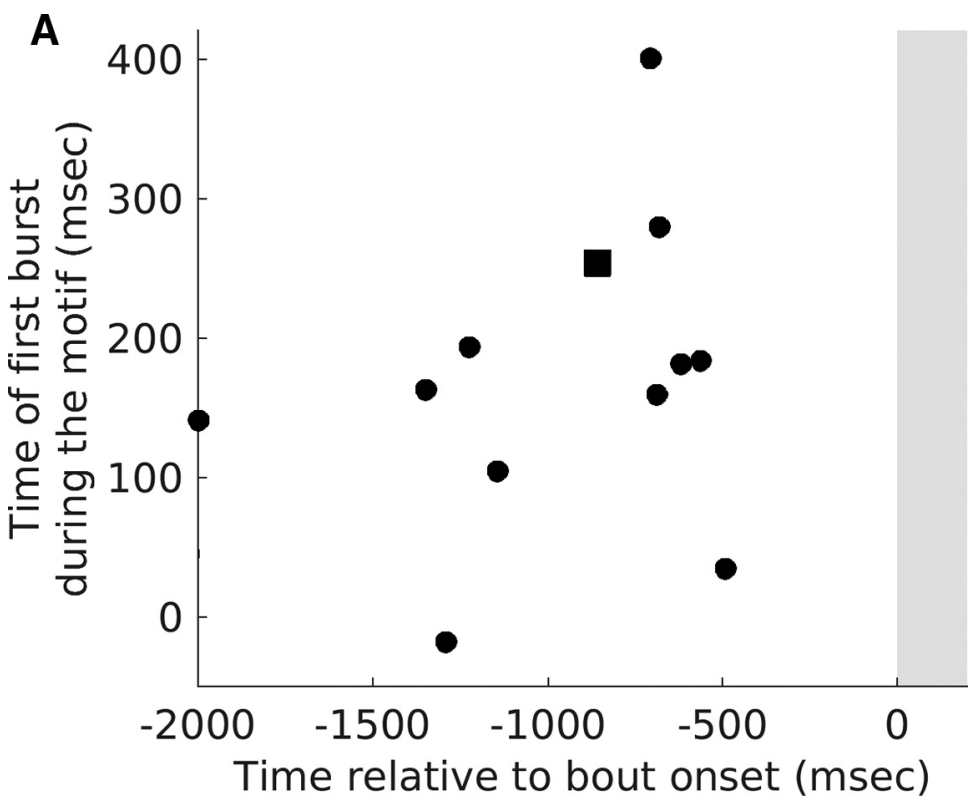

Figure 8. Time at which $\mathrm{HVC}_{x}$ neurons started to show pre-bout decreases was not correlated with the time of first burst of the same neurons during the motif. $\boldsymbol{A}$, Time of the first motif-related burst of individual $\mathrm{HVC}_{\mathrm{X}}$ neurons plotted as a function of the time they started to show a pre-bout decrease in activity (time estimated using the median time of last spike shown in Fig. 6C). ach symbol represents one $\mathrm{HVC}_{\mathrm{x}}$ neuron that showed a significant pre-bout decrease in activity. Square represents neuron shown

A

Figure 9. Solitary INs have longer intervals to the next syllable and are acoustically more distant from the last IN. $\boldsymbol{A}$, Individual thes of bouts was significantly different ( $p<0.05$, Kruskal-Wallis test). $\boldsymbol{B}$, Individual symbols represent data from individual paring the median acoustic distance of the first IN from the last IN during IN song bouts and solitary IN bouts. Whiskers represent the interquartile range. Filled symbols represent birds in which data from the two types of bouts was significantly different ( $p<0.05$, Kruskal-Wallis test).

such neurons. Assuming the presence of specialized $\mathrm{HVC}_{\mathrm{RA}}$ neurons with similar preparatory roles, such neurons would be very different from the $\mathrm{HVC}_{\mathrm{RA}}$ neurons that are thought to encode "time" in song (Fee et al., 2004; Long et al., 2010). In addition to differences in firing patterns ("ramping-up" like activity vs stereotyped sparse bursting), the connectivity of these neurons would also be different, reflecting their different functional roles.

\section{Functions of pre-bout activity}

Independent of the mechanism for generating pre-bout activity, the current study suggests that pre-bout activity is important for successful song initiation. Lower levels of pre-bout activity before the first IN of solitary IN bouts was correlated with no progression to song (Figs. 4, 7). Compared with IN song bouts, the first 
IN in a solitary IN bout was further away from the last IN in terms of timing and acoustic structure (Fig. 9). Both of these aspects are inversely correlated with the progression of INs to song (Rajan and Doupe, 2013), suggesting that pre-bout activity in HVC may influence IN progression by altering the properties of the first IN. Further studies disrupting pre-bout activity will help to determine the exact functions of pre-bout activity.

Overall, this study suggests that changes in activity in premotor nucleus HVC occurring hundreds of milliseconds before song bout onset are important for successful song bout initiation. Such changes could reflect preparatory activity important for initiation of the learned song sequence. These results highlight the potential importance of HVC for song initiation and suggest more parallels with mammalian cortical basal ganglia circuits involved in movement initiation. Moreover, along with a previous study suggesting the presence of preparatory vocalizations before song initiation (Rajan and Doupe, 2013), this study suggests that preparatory neural activity is a feature of learned movement sequence initiation as well. Therefore, the zebra finch could serve as an excellent model system in which to better understand preparatory activity and its role in initiation of naturally learned movement sequences.

\section{References}

Akutagawa E, Konishi M (2010) New brain pathways found in the vocal control system of a songbird. J Comp Neurol 518:3086-3100. CrossRef Medline

Bankman IN, Johnson KO, Schneider W (1993) Optimal detection, classification, and superposition resolution in neural waveform recordings. IEEE Trans Biomed Eng 40:836-841. CrossRef Medline

Bolhuis JJ, Okanoya K, Scharff C (2010) Twitter evolution: converging mechanisms in birdsong and human speech. Nat Rev Neurosci 11:747759. CrossRef Medline

Cardin JA, Schmidt MF (2004) Noradrenergic inputs mediate state dependence of auditory responses in the avian song system. J Neurosci 24:77457753. CrossRef Medline

Chen TW, Li N, Daie K, Svoboda K (2017) A map of anticipatory activity in mouse motor cortex. Neuron 94:866-879.e4. CrossRef Medline

Churchland MM, Shenoy KV (2007) Delay of movement caused by disruption of cortical preparatory activity. J Neurophysiol 97:348-359. CrossRef Medline

Churchland MM, Santhanam G, Shenoy KV (2006) Preparatory activity in premotor and motor cortex reflects the speed of the upcoming reach. J Neurophysiol 96:3130-3146. CrossRef Medline

Churchland MM, Cunningham JP, Kaufman MT, Ryu SI, Shenoy KV (2010) Cortical preparatory activity: representation of movement or first $\operatorname{cog}$ in a dynamical machine? Neuron 68:387-400. CrossRef Medline

Coleman MJ, Vu ET (2005) Recovery of impaired songs following unilateral but not bilateral lesions of nucleus uvaeformis of adult zebra finches. J Neurobiol 63:70-89. CrossRef Medline

Danish HH, Aronov D, Fee MS (2017) Rhythmic syllable-related activity in a songbird motor thalamic nucleus necessary for learned vocalizations. PLoS One 12:e0169568. CrossRef Medline

Day BL, Rothwell JC, Thompson PD, Maertens de Noordhout A, Nakashima K, Shannon K, Marsden CD (1989) Delay in the execution of voluntary movement by electrical or magnetic brain stimulation in intact man. Brain 112:649-663. CrossRef Medline

Doupe AJ, Kuhl PK (1999) Birdsong and human speech: common themes and mechanisms. Annu Rev Neurosci 22:567-631. CrossRef Medline

Dutar P, Vu HM, Perkel DJ (1998) Multiple cell types distinguished by physiological, pharmacological, and anatomic properties in nucleus $\mathrm{HVc}$ of the adult zebra finch. J Neurophysiol 80:1828-1838. CrossRef Medline

Fee MS, Scharff C (2010) The songbird as a model for the generation and learning of complex sequential behaviors. ILAR J 51:362-377. CrossRef Medline

Fee MS, Kozhevnikov AA, Hahnloser RH (2004) Neural mechanisms of vocal sequence generation in the songbird. Ann N Y Acad Sci 1016:153-170. CrossRef Medline

Fortune ES, Margoliash D (1995) Parallel pathways and convergence onto
HVc and adjacent neostriatum of adult zebra finches (Taeniopygia guttata). J Comp Neurol 360:413-441. CrossRef Medline

Goldberg JH, Fee MS (2012) A cortical motor nucleus drives the basal ganglia-recipient thalamus in singing birds. Nat Neurosci 15:620-627. CrossRef Medline

Guo ZV, Li N, Huber D, Ophir E, Gutnisky D, Ting JT, Feng G, Svoboda K (2014) Flow of cortical activity underlying a tactile decision in mice. Neuron 81:179-194. CrossRef Medline

Hahnloser RH, Fee MS (2007) Sleep-related spike bursts in HVC are driven by the nucleus interface of the nidopallium. J Neurophysiol 97:423-435. CrossRef Medline

Hahnloser RH, Kozhevnikov AA, Fee MS (2002) An ultra-sparse code underlies the generation of neural sequences in a songbird. Nature 419:6570. CrossRef Medline

Hessler NA, Doupe AJ (1999) Singing-related neural activity in a dorsal forebrain-basal ganglia circuit of adult zebra finches. J Neurosci 19: 10461-10481. CrossRef Medline

Jin X, Costa RM (2010) Start/stop signals emerge in nigrostriatal circuits during sequence learning. Nature 466:457-462. CrossRef Medline

Jin X, Costa RM (2015) Shaping action sequences in basal ganglia circuits. Curr Opin Neurobiol 33:188-196. CrossRef Medline

Kao MH, Wright BD, Doupe AJ (2008) Neurons in a forebrain nucleus required for vocal plasticity rapidly switch between precise firing and variable bursting depending on social context. J Neurosci 28:1323213247. CrossRef Medline

Kojima S, Kao MH, Doupe AJ (2013) Task-related "cortical" bursting depends critically on basal ganglia input and is linked to vocal plasticity. Proc Natl Acad Sci U S A 110:4756-4761. CrossRef Medline

Kornhuber HH, Deecke L (1965) Hirnpotentialänderungen bei Willkürbewegungen und passiven bewegungen des menschen: bereitschaftspotential und reafferente potentiale. Pflüg Arch Eur J Physiol 284:1-17.

Kosche G, Vallentin D, Long MA (2015) Interplay of inhibition and excitation shapes a premotor neural sequence. J Neurosci 35:1217-1227. CrossRef Medline

Kozhevnikov AA, Fee MS (2007) Singing-related activity of identified HVC neurons in the zebra finch. J Neurophysiol 97:4271-4283. CrossRef Medline

Kravitz AV, Freeze BS, Parker PR, Kay K, Thwin MT, Deisseroth K, Kreitzer AC (2010) Regulation of parkinsonian motor behaviors by optogenetic control of basal ganglia circuitry. Nature 466:622-626. CrossRef Medline

Lee IH, Assad JA (2003) Putaminal activity for simple reactions or selftimed movements. J Neurophysiol 89:2528-2537. CrossRef Medline

Lehky SR, Sejnowski TJ, Desimone R (2005) Selectivity and sparseness in the responses of striate complex cells. Vision Res 45:57-73. CrossRef Medline

Leonardo A, Fee MS (2005) Ensemble coding of vocal control in birdsong. J Neurosci 25:652-661. CrossRef Medline

Lewandowski BC, Schmidt M (2011) Short bouts of vocalization induce long-lasting fast $\gamma$ oscillations in a sensorimotor nucleus. J Neurosci 31: 13936-13948. CrossRef Medline

Li N, Chen TW, Guo ZV, Gerfen CR, Svoboda K (2015) A motor cortex circuit for motor planning and movement. Nature 519:51-56. CrossRef Medline

Li N, Daie K, Svoboda K, Druckmann S (2016) Robust neuronal dynamics in premotor cortex during motor planning. Nature 532:459-464. CrossRef Medline

Long MA, Jin DZ, Fee MS (2010) Support for a synaptic chain model of neuronal sequence generation. Nature 468:394-399. CrossRef Medline

Maimon G, Assad JA (2006) Parietal area 5 and the initiation of self-timed movements versus simple reactions. J Neurosci 26:2487-2498. CrossRef Medline

Margoliash D (1997) Functional organization of forebrain pathways for song production and perception. J Neurobiol 33:671-693. CrossRef Medline

McCasland JS (1987) Neuronal control of bird song production. J Neurosci 7:23-39. CrossRef Medline

Mooney R, Prather JF (2005) The HVC microcircuit: the synaptic basis for interactions between song motor and vocal plasticity pathways. J Neurosci 25:1952-1964. CrossRef Medline

Naie K, Hahnloser RH (2011) Regulation of learned vocal behavior by an auditory motor cortical nucleus in juvenile zebra finches. J Neurophysiol 106:291-300. CrossRef Medline 
Nottebohm F, Kelley DB, Paton JA (1982) Connections of vocal control nuclei in the canary telencephalon. J Comp Neurol 207:344-357. CrossRef Medline

Okubo TS, Mackevicius EL, Payne HL, Lynch GF, Fee MS (2015) Growth and splitting of neural sequences in songbird vocal development. Nature 528:352-357. CrossRef Medline

Ölveczky BP, Otchy TM, Goldberg JH, Aronov D, Fee MS (2011) Changes in the neural control of a complex motor sequence during learning. J Neurophysiol 106:386-397. CrossRef Medline

Price PH (1979) Developmental determinants of structure in zebra finch song. J Comp Physiol Psychol 93:260. CrossRef

Rajan R, Doupe AJ (2013) Behavioral and neural signatures of readiness to initiate a learned motor sequence. Curr Biol 23:87-93. CrossRef Medline

Riehle A, Requin J (1989) Monkey primary motor and premotor cortex: single-cell activity related to prior information about direction and extent of an intended movement. J Neurophysiol 61:534-549. CrossRef Medline

Roberts TF, Hisey E, Tanaka M, Kearney MG, Chattree G, Yang CF, Shah NM, Mooney R (2017) Identification of a motor-to-auditory pathway important for vocal learning. Nat Neurosci 20:978-986. CrossRef Medline

Romo R, Schultz W (1987) Neuronal activity preceding self-initiated or externally timed arm movements in area 6 of monkey cortex. Exp Brain Res 67:656-662. Medline

Schmidt MF (2003) Pattern of interhemispheric synchronization in HVc during singing correlates with key transitions in the song pattern. J Neurophysiol 90:3931-3949. CrossRef Medline

Schultz W, Romo R (1992) Role of primate basal ganglia and frontal cortex in the internal generation of movements. Exp Brain Res 91:363-384. Medline
Shenoy KV, Kaufman MT, Sahani M, Churchland MM (2011) A dynamical systems view of motor preparation: implications for neural prosthetic system design. Prog Brain Res 192:33-58. CrossRef Medline

Shenoy KV, Sahani M, Churchland MM (2013) Cortical control of arm movements: a dynamical systems perspective. Annu Rev Neurosci 36: 337-359. CrossRef Medline

Simpson HB, Vicario DS (1990) Brain pathways for learned and unlearned vocalizations differ in zebra finches. J Neurosci 10:1541-1556. CrossRef Medline

Sossinka R, Böhner J (1980) Song types in the zebra finch Poephila guttata castanotis. Z Für Tierpsychol 53:123-132. CrossRef

Swadlow HA (1998) Neocortical efferent neurons with very slowly conducting axons: strategies for reliable antidromic identification. J Neurosci Methods 79:131-141. CrossRef Medline

Tanji J, Evarts EV (1976) Anticipatory activity of motor cortex neurons in relation to direction of an intended movement. J Neurophysiol 39:10621068. CrossRef Medline

Vyssotski AL, Stepien AE, Keller GB, Hahnloser RH (2016) A neural code that is isometric to vocal output and correlates with its sensory consequences. PLoS Biol 14:e2000317. CrossRef Medline

Williams H, Vicario DS (1993) Temporal patterning of song production: participation of nucleus uvaeformis of the thalamus. J Neurobiol 24:903912. CrossRef Medline

Woolley SC, Rajan R, Joshua M, Doupe AJ (2014) Emergence of contextdependent variability across a basal ganglia network. Neuron 82:208-223. CrossRef Medline

Yu AC, Margoliash D (1996) Temporal hierarchical control of singing in birds. Science 273:1871-1875. CrossRef Medline 